Article

\title{
Evaluation of Visual-Evoked Cerebral Metabolic Rate of Oxygen as a Diagnostic Marker in Multiple Sclerosis
}

\author{
Nicholas A. Hubbard ${ }^{1, *}$, Yoel Sanchez Araujo ${ }^{1}$, Camila Caballero ${ }^{1}$, Minhui Ouyang ${ }^{2}$, \\ Monroe P. Turner ${ }^{3}$, Lyndahl Himes ${ }^{3}$, Shawheen Faghihahmadabadi ${ }^{3}$, Binu P. Thomas ${ }^{3,4}$, \\ John Hart Jr. ${ }^{3,5,6}$, Hao Huang ${ }^{2}$, Darin T. Okuda ${ }^{3,5}$ and Bart Rypma ${ }^{3,6}$ \\ 1 Massachusetts Institute of Technology, Cambridge, MA 02139, USA; ysa@mit.edu (Y.S.A.); \\ csquared@mit.edu (C.C.) \\ 2 Children's Hospital of Philadelphia, University of Pennsylvania School of Medicine, Philadelphia, PA 19104, \\ USA; ouyangm@email.chop.edu (M.O.); huangh6@email.chop.edu (H.H.) \\ 3 University of Texas at Dallas, Dallas, TX 75080, USA; monroe.p.turner@utdallas.edu (M.P.T.); \\ lyndahl.himes@utdallas.edu (L.H.); shawheen.fahih@utdallas.edu (S.F.); \\ binu.thomas@utsouthwestern.edu (B.P.T.); jhart@utdallas.edu (J.H.); \\ darin.okuda@utsouthwestern.edu (D.T.O.); bart.rypma@utdallas.edu (B.R.) \\ 4 University of Texas Southwestern Medical Center, Advanced Imaging Research Center, Dallas, TX 75235, USA \\ 5 Department of Neurology and Neurothreapeutics, University of Texas Southwestern Medical Center, Dallas, \\ TX 75235, USA \\ 6 Department of Psychiatry, University of Texas Southwestern Medical Center, Dallas, TX 75235, USA \\ * Correspondence: nhubbard@mit.edu; Tel.: +1-617-324-371
}

Academic Editor: Evanthia Bernitsas

Received: 31 March 2017; Accepted: 5 June 2017; Published: 11 June 2017

\begin{abstract}
A multiple sclerosis (MS) diagnosis often relies upon clinical presentation and qualitative analysis of standard, magnetic resonance brain images. However, the accuracy of MS diagnoses can be improved by utilizing advanced brain imaging methods. We assessed the accuracy of a new neuroimaging marker, visual-evoked cerebral metabolic rate of oxygen $(\mathrm{veCMRO})$, in classifying $\mathrm{MS}$ patients and closely age- and sex-matched healthy control (HC) participants. MS patients and HCs underwent calibrated functional magnetic resonance imaging (cfMRI) during a visual stimulation task, diffusion tensor imaging, $\mathrm{T}_{1}$ - and $\mathrm{T}_{2}$-weighted imaging, neuropsychological testing, and completed self-report questionnaires. Using resampling techniques to avoid bias and increase the generalizability of the results, we assessed the accuracy of veCMRO ${ }_{2}$ in classifying MS patients and $\mathrm{HCs}$. veCMRO classification accuracy was also examined in the context of other evoked visuofunctional measures, white matter microstructural integrity, lesion-based measures from $\mathrm{T}_{2}$-weighted imaging, atrophy measures from $\mathrm{T}_{1}$-weighted imaging, neuropsychological tests, and self-report assays of clinical symptomology. veCMRO $\mathrm{O}_{2}$ was significant and within the top $16 \%$ of measures (43 total) in classifying MS status using both within-sample ( $82 \%$ accuracy) and out-of-sample (77\% accuracy) observations. High accuracy of veCMRO $\mathrm{N}_{2}$ in classifying MS demonstrated an encouraging first step toward establishing veCMRO 2 as a neurodiagnostic marker of MS.
\end{abstract}

Keywords: calibrated functional magnetic resonance imaging; multiple sclerosis; diagnosis; visual system; metabolism 


\section{Introduction}

Current procedures for diagnosing multiple sclerosis (MS) rely primarily upon clinical presentation and qualitative analysis of standard, medical-grade (e.g., lower resolution) magnetic resonance structural, brain images, e.g., [1]. It has been demonstrated that the diagnostic accuracy of MS can be improved when providers implement advanced neuroimaging techniques and analyses that are not presently common in clinical practice, e.g., [2], see also [3]. Further, research using advanced neuroimaging techniques has demonstrated that these techniques can be more sensitive than their traditional counterparts in detecting subtle changes associated with very early manifestations of MS, e.g., $[4,5]$. Here, we investigated the accuracy of an advanced neuroimaging technique never before used in MS, calibrated functional magnetic resonance imaging (cfMRI), to classify MS patients and closely age- and sex-matched healthy controls (HCs). Specifically, we focused our analyses upon the ability of a new neuroimaging marker, visual-evoked cerebral metabolic rate of oxygen $\left(\mathrm{veC} \mathrm{MRO}_{2}\right)$, to accurately discriminate between MS patients and HCs.

cfMRI is a relatively new neuroimaging technique that capitalizes upon established relationships between blood-oxygen-level dependent (BOLD) signal and cerebral blood flow (CBF) in order to estimate steady-state, oxygen metabolism [6,7] see [8]. The technique gets its name from the use of a BOLD-calibration parameter, often acquired during a gas-inhalation challenge. The $\mathrm{CMRO}_{2}$ metric permitted by cfMRI offers several advantages over the more commonly used BOLD signal. First, $\mathrm{CMRO}_{2}$ offers physiological specificity. $\mathrm{CMRO}_{2}$ represents a true physiological process, oxygen metabolism, whereas BOLD reflects a confluence of processes and as such, is physiologically non-specific. Second, calibration-derived $\mathrm{CMRO}_{2}$ is strongly tied to electrical and chemical neural activity, e.g., [9-15], whereas an appreciable component of BOLD signal is unexplained by neural activity, e.g., [16-20], see [21], but see [9]. Finally, $\mathrm{CMRO}_{2}$ measures are not dependent upon the hemodynamic assumptions of BOLD, making them optimal measures of brain function in populations with atypical hemodynamics, like MS, e.g., [22,23], see [24].

Evaluating $\mathrm{CMRO}_{2}$ as a diagnostic marker of MS is particularly relevant for these patients because MS is associated with changes to neurometabolism. Neuroimaging research has produced considerable evidence of altered neurometabolism in MS, e.g., [25-29]. In one study, Ge and colleagues [30] demonstrated decreases in brain-wide resting $\mathrm{CMRO}_{2}$ for $\mathrm{MS}$ patients relative to $\mathrm{HCs}$. Some neuroimaging studies have shown that neurometabolic alterations were related to white matter macrostructural (i.e., lesions, e.g., [30]) or microstructural damage in MS, e.g., [27,28]. For example, magnetic resonance spectroscopy in centrum semiovale white matter has shown that $N$-acetylaspertate (NAA) and NAA: creatine ratios were strongly related to diffusion-weighted indices of white matter structural integrity in MS patients [27].

It is intuitive that MS patients would show differences in in vivo neurometabolism when considering that postmortem analyses have revealed extensive alterations to the mitochondria in lesioned and non-lesioned MS neural tissue [31-33], see [34-36]. For instance, Singhal and colleagues [33] found decreases in postmortem NAA, a partial marker of neuronal respiratory capacity, and decreases in electron transport subunit proteins across lesioned and non-lesioned MS grey matter, relative to matched control participants' grey matter. Taken together, the results of postmortem and in vivo neuroimaging studies demonstrate that neurometabolic alterations are generally featured in MS.

Evaluating veCMRO $\mathrm{C}_{2}$ should also be particularly relevant as a diagnostic marker of MS because MS is marked by alterations to the neural substrate of the visual system, see [37-40] see also [5]. The use of advanced imaging techniques such as high-resolution structural brain imaging, optical coherence tomography (OCT), functional magnetic resonance imaging (fMRI), and diffusion tensor imaging (DTI) has revealed that visual system alterations exist even in MS patients without visual disturbances or a history of optic neuritis (a clinical syndrome closely linked to MS and marked by visual impairment and visual pathway insult). Indeed, there are MS-related structural alterations to both early (e.g., retinae) and later (e.g., optic radiations) portions of the afferent visual pathway, and alterations to visuocortical activity in patients without a history of optic neuritis see [39]. For instance, Alshowaier 
and colleagues [41] used electroencephalogram recordings to show that MS patients without a history of optic neuritis demonstrated delayed inion channel, multifocal visual-evoked electrical potentials relative to age- and sex-matched HCs. Previous work in our laboratory has also revealed alterations to visual cortex BOLD signal during visual stimulation in MS patients with normal or corrected-to-normal vision compared to matched HCs [42], see also [43]. Together, structural and functional imaging results suggest that changes to the visual system are a robust marker of MS pathology.

MS is associated with changes to neurometabolism and alterations to the neural substrate of the visual system. Thus, visual-evoked oxygen metabolism signals in visual cortex (i.e., veCMRO $\mathrm{V}_{2}$ ) should be a diagnostically relevant marker of MS. We assessed the extent to which veCMRO $\mathrm{C}_{2}$ signals could be used to discriminate between MS patients and HCs. The classification accuracy of veCMRO was examined in the context of other variables commonly assayed in MS, including measures of neurological insult (e.g., gross lesion volume, parenchymal atrophy), neuropsychological change (e.g., Brief Repeatable Battery of Neuropsychological Tests [44]), and self-report symptom measures (e.g., subjective fatigue). We tested the extent to which veCMRO classify MS status using both within-sample and out-of-sample observations.

\section{Materials and Methods}

\subsection{Participants}

Participants between the ages of 18 and 65 were recruited for this study. Participants were required to be free of MR-contraindicators, concurrent substance abuse, have normal or corrected-to-normal vision, and speak fluent English. Because study procedures included a gas-inhalation challenge (see Section 2.4), participant selection was limited to non-smokers. Participants did not have histories of respiratory or pulmonary problems, cerebral vascular issues, or cardiac problems. Participants were required to have a score greater than 21 on the telephone interview for cognitive status [45]. Thirty-one participants in total met the inclusion criteria.

Twelve MS patients meeting the above criteria were recruited from the Clinical Center for Multiple Sclerosis at the University of Texas Southwestern Medical Center. Eleven patients had a diagnosis of relapsing-remitting MS and one patient had a diagnosis of secondary-progressive MS. Patients were required to be at least 1 month past their most recent exacerbation and their last corticosteroid treatment. Patients were recruited who did not report a history of optic neuritis. Patients without a history of optic neuritis were specifically selected so as to limit additional variability from attributed to severe, anterior visual pathway damage/dysfunction (e.g., such as that resulting from conduction block) and potential visual impairment. All MS patients' vision was normal or corrected-to-normal. Two patients withdrew or declined to undergo the gas challenge (total $n=10$ ).

Nineteen HC participants were recruited from the Dallas-Fort Worth Metroplex via email, posted flyers, and word-of-mouth. These participants were evaluated for the general inclusion/exclusion criteria described above. Three HCs did not undergo the scanning protocol because of exclusions discovered after study enrollment (e.g., concussion history revealed after pre-screening, incidental MR finding). Two HCs withdrew or declined to undergo the gas challenge. During imaging processing (see Section 2.5), one HC's functional images failed to appropriately register to their anatomical image after multiple attempts, so this person was excluded. Thirteen HCs $(n=13)$ remained for subsequent analyses. These participants were closely age- and sex-matched to the MS patients (see Table 1). 
Table 1. Group Characteristics.

\begin{tabular}{llll}
\hline & MS & HC & $p$ \\
\hline Age & $50.10(3.35)$ & $50.77(3.35)$ & $0.885^{\mathrm{a}}$ \\
MFIS & $39.10(7.62)$ & $20.54(4.57)$ & $0.046^{\mathrm{a}}$ \\
Sex (\% female) & $90.00 \%$ & $84.62 \%$ & $0.704^{\mathrm{b}}$ \\
TICS Score & $27.00(0.82)$ & $28.08(1.43)$ & $0.520^{\mathrm{a}}$ \\
Age of MS Onset & $38.67(2.42)$ & - & - \\
Disease Duration & $118.80(19.32)$ & - & - \\
Last Flare-up & $28.60(11.32)$ & - & - \\
Neurological Disability Score & $15.70(3.71)$ & - & - \\
Disease Modifying Therapies & & & - \\
$\quad$ Dalfampridine & $50 \%$ & - & - \\
$\quad$ Dimethyl fumarate & $10 \%$ & - & - \\
$\quad$ Fingolimod & $20 \%$ & - & - \\
$\quad$ Glatiramer acetate & $10 \%$ & - &
\end{tabular}

Mean (SEM). Age in years. MFIS = modified fatigue impact score total. Sex in percent female. TICS score $=$ telephone interview for cognitive status score. Age of MS onset in years. Disease duration and last flare-up in months. Neurological disability score measured by self-report [46]. Disease modifying therapies represent percent of participants reporting use of therapy. ${ }^{a} p$-value based upon independent samples $t$-test. ${ }^{b} p$-value based upon Pearson $\chi^{2}$.

\subsection{Study Procedures}

Study procedures were approved by the University of Texas Southwestern Medical Center Institutional Review Board. Recruitment numbers were approximated based upon previous research showing sufficient power to demonstrate group changes in calibrated fMRI (cfMRI) contrasts with similar sample sizes [22,23]. Participants meeting inclusion criteria were asked to refrain from caffeine use at least two hours before their scheduled appointment time, e.g., [47]. They were also asked not to consume alcohol on the same calendar day before their scheduled appointment. Participants gave written informed consent before undergoing procedures and were compensated for their time. Participants underwent functional and structural neuroimaging on a Philips 3-Tesla magnet (Philips Medical Systems, Best, The Netherlands) with an 8-channel SENSE radiofrequency head coil. Foam padding was placed around the head to minimize motion during MRI scan acquisition. Participants completed standard neuropsychological tests (e.g., Brief Repeatable Battery of Neuropsychological tests [44]) and self-report measures regarding their general health and symptomology (i.e., SF-36 [48], Modified Fatigue Impact Scale (MFIS, [49]); see Table 2 for a complete list of model variables).

Table 2. Predictor Variables.

\begin{tabular}{|c|c|c|}
\hline Predictor (Units if Available) & Predictor Category & What Predictor Measures \\
\hline Normalized Grey Matter Volume $\left(\mathrm{mm}^{3}\right)$ & MR Image & Total grey matter volume normalized to skull \\
\hline Normalized White Matter Volume $\left(\mathrm{mm}^{3}\right)$ & MR Image & Total white matter volume normalized to skull \\
\hline Normalized Whole Brain Volume $\left(\mathrm{mm}^{3}\right)$ & MR Image & Total brain volume normalized to skull \\
\hline Skeleton FA (proportion) & MR Image & Proportion of anisotropic diffusion \\
\hline Skeleton $\mathrm{MD}\left(\mathrm{mm}^{2} / \mathrm{s}\right)$ & MR Image & Average Diffusion in primary diffusion axes \\
\hline Skeleton RD $\left(\mathrm{mm}^{2} / \mathrm{s}\right)$ & MR Image & Diffusion orthogonal to primary diffusion axis \\
\hline $\mathrm{T}_{2}$-FLAIR spatially distinct lesion count & MR Image & Total number of spatially distinct lesions \\
\hline veBOLD ( $\%$ signal change) & MR Image & Visual cortex BOLD response to visual stimulation task \\
\hline veCBF (\% signal change) & MR Image & Visual cortex CBF response to visual stimulation task \\
\hline veCMRO ${ }_{2}$ ( $\%$ signal change) & MR Image & Visual cortex $\mathrm{CMRO}_{2}$ response to visual stimulation task \\
\hline ven (proportion) & MR Image & Visual cortex neural-vascular coupling \\
\hline 10/36 Delayed Recall (total correct after $15 \mathrm{~min}$ ) & Neuropsych & Visuospatial memory/learning and delayed recall \\
\hline 10/36 Immediate Recall (total correct) & Neuropsych & Visuospatial memory/learning \\
\hline Number Comparison (items completed) & Neuropsych & Processing speed \\
\hline
\end{tabular}


Table 2. Cont.

\begin{tabular}{lcl}
\hline Predictor (Units if Available) & Predictor Category & What Predictor Measures \\
\hline Paced Auditory Serial Addition Test 2 (\% correct) & Neuropsych & Processing speed and selective/sustained attention \\
Paced Auditory Serial Addition Test 3 (\% correct) & Neuropsych & Processing speed and selective/sustained attention \\
Selective Reminding Task Delayed (items recalled) & Neuropsych & Verbal learning and memory \\
Selective Reminding Task Long-term Storage (items recalled) & Neuropsych & Verbal learning and long-term memory \\
Symbol-digit Modalities Test (items completed) & Neuropsych & Sustained attention and concentration \\
Trail Making Task Form A (s) & Neuropsych & Visual search, attention, mental flexibility, and motor function \\
Trail Making Task Form B (s) & Neuropsych & Visual search, attention, mental flexibility, and motor function \\
Trail Making Task Form B-A (s) & Neuropsych & Visual search, attention, mental flexibility, and motor function \\
WAIS-III Digit Span Backward (items completed) & Neuropsych & Short-term, working memory \\
WAIS-III Digit Span Forward (items completed) & Neuropsych & Short-term, working memory \\
WAIS-III Digit Span Total (items completed) & Neuropsych & Short-term, working memory \\
WAIS-III Digit symbol coding (items completed) & Neuropsych & Performance subtest of WAIS \\
Modified Fatigue Impact Score & Symptoms & Fatigue symptomology \\
SF-36 Bodily Pain Scale & Symptoms & General measure of bodily pain \\
SF-36 Emotion & Symptoms & Role limitations due to emotional problems \\
SF-36 General Health Scale & Symptoms & General measure of health wellbeing \\
SF-36 Mental Health Scale & Symptoms & General measure of mental health \\
SF-36 Physical Functioning Scale & Symptoms & General measure of physical functioning \\
SF-36 Role Physical Function Scale & Symptoms & Role limitations due to physical problems \\
SF-36 Social Functioning Scale & Symptoms & General measure of social functioning \\
SF-36 Vitality Scale & Symptoms & General measure of energy/fatigue
\end{tabular}

FLAIR = Fluid-attenuated inversion recovery. WAIS = Wechsler adult intelligent scale. SF-36 = Short-form health survey. MR Image = magnetic resonance image; Neuropsych = neuropsychological test; Symptoms = self-report general health and symptom measures. Explanations of neuropsychological tests and symptom measures taken from $[44,48,50,51]$.

\section{3. cfMRI Parameters and Theory}

Dual-echo pseudocontinuous arterial spin labeling (pCASL) and BOLD images (together referred to as dual-echo images) were acquired using an interleaved echo scanning protocol see [7,52]. Together, the perfusion (Echo 1) and BOLD-weighted (Echo 2) images along with biophysical modeling procedures allowed for estimation of $\mathrm{CMRO}_{2}$ and a neural-vascular coupling coefficient $(n$, see [8]) associated with steady-state, neural stimulation [5,7]. One task run of dual-echo imaging data and one gas-challenge run of dual-echo imaging data were collected using the following parameters: Echo 1: labeling duration $1650 \mathrm{~ms}$, labeling flip angle $18^{\circ}$, labeling gap $=63.5 \mathrm{~mm}, 3.44 \times 3.44 \times 5 \mathrm{~mm}$ voxel, repetition time $(\mathrm{TR})=4000 \mathrm{~ms}$, echo time $(\mathrm{TE})=14 \mathrm{~ms}, 1525 \mathrm{~ms}$ post-label delay, $0 \mathrm{~mm}$ slice gap. Echo 2: $90^{\circ}$ flip angle, $3.44 \times 3.44 \times 5 \mathrm{~mm}$ voxel, $\mathrm{TR}=4000 \mathrm{~ms}, \mathrm{TE}=40 \mathrm{~ms}, 0 \mathrm{~mm}$ slice gap. Total scan time for the visual stimulation task $=600 \mathrm{~s}$ (72 dual-echo dynamics). Total scan time for the gas challenge $=624 \mathrm{~s}$ (75 dual-echo dynamics).

Estimations of $\mathrm{CMRO} 2$ and $n$ were based upon the Davis model of BOLD signal change [6,7]:

$$
\frac{\Delta S}{S_{0}}=M\left(\left(1-\frac{\Delta \mathrm{CBF}}{\mathrm{CBF}_{0}}\right)^{\alpha-\beta}\left(\frac{\Delta \mathrm{CMRO}_{2}}{\mathrm{CMRO}_{2 \mid 0}}\right)^{\beta}\right)
$$

where $\Delta \mathrm{x} / \mathrm{x}_{0}$ denotes a change from baseline, $\alpha$ is an empirically derived constant linking cerebral blood flow and cerebral blood volume, and $\beta$ is an empirically derived constant related to vascular exchange and susceptibility of deoxyhemoglobin at specific field strengths (e.g., [53-55]). We assumed $\alpha=0.38$ [56] and $\beta=1.3$ [52]; these values were chosen because they have been shown to be sensitive to group differences in neurophysiology $[22,23]$. Also, these values have previously demonstrated group-equivalence in the estimation of $M$, e.g., [22,23]. $M$ is a subject-specific scaling factor dependent upon the washout resting deoxyhemoglobin see [8]. $M$ was estimated in each participant, using the gas challenge detailed below.

The measurement of BOLD, CBF, and $M$ allows for the estimation of $\mathrm{CMRO}_{2}$. Here, $\triangle \mathrm{CMRO}_{2}$ reflects the visual task-related change in neurometabolism of oxygen from resting baseline:

$$
\frac{\Delta \mathrm{CMRO}_{2}}{\mathrm{CMRO}_{2 \mid 0}}=\left(1-\frac{\frac{\Delta \mathrm{BOLD}}{\mathrm{BOLD}_{0}}}{M}\right)^{1 / \beta}\left(\frac{\Delta \mathrm{CBF}}{\mathrm{CBF}_{0}}\right)^{1-\alpha / \beta}
$$


where $\Delta \mathrm{x} / \mathrm{x}_{0}$ reflects percent change of signal during task compared to resting baseline. With the estimation of $\Delta \mathrm{CMRO}_{2}, n$, may also be estimated:

$$
n=\frac{\frac{\Delta \mathrm{CBF}}{\mathrm{CBF}_{0}}}{\frac{\Delta \mathrm{CMRO}_{2}}{\mathrm{CMRO}_{2 \mid 0}}}
$$

thus, $n$ reflects per unit output of $\Delta \mathrm{CBF}$ per unit input of $\Delta \mathrm{CMRO}_{2}$ see [8].

\section{4. cfMRI Task and Gas Challenge}

Participants completed a visual stimulation task during dual-echo task imaging. This task was chosen for two reasons. First, differences in the functional response to visual stimulation have been observed in MS visual cortex see [42,57]. Second, because this task required minimal effort, group differences in performance were not expected to be a factor.

Participants were trained on the task before entering the MR environment. During the task, participants focused on a fixation cross at the center of their visual field. Participants were required to respond via bilateral, thumb-button press when a change in the luminance of the fixation cross occurred. This task was used in order to control the center of the participants' visual field $[22,23,58]$. Change in luminance was jittered and occurred every 2, 3, 4, or $6 \mathrm{~s}$. Visual stimulation occurred in a block format. There were 6 visual stimulation task blocks consisting of $60 \mathrm{~s}$ of continual annulus flickering in the participants' near-foveal visual field. Annuli alternated at orthogonal orientations $\left(0\right.$ to $\left.90^{\circ}\right)$ to avoid neural adaptation [58]. Alterations occurred at a constant frequency of $8 \mathrm{~Hz}$ because both electrochemical neural activity and BOLD signal have been shown to peak at this frequency, potentially yielding the greatest signal-to-noise estimates, e.g., [59,60]. Rest blocks were jittered at 32 , 34, 36, 38, and 40 s intervals (see Figure 1).

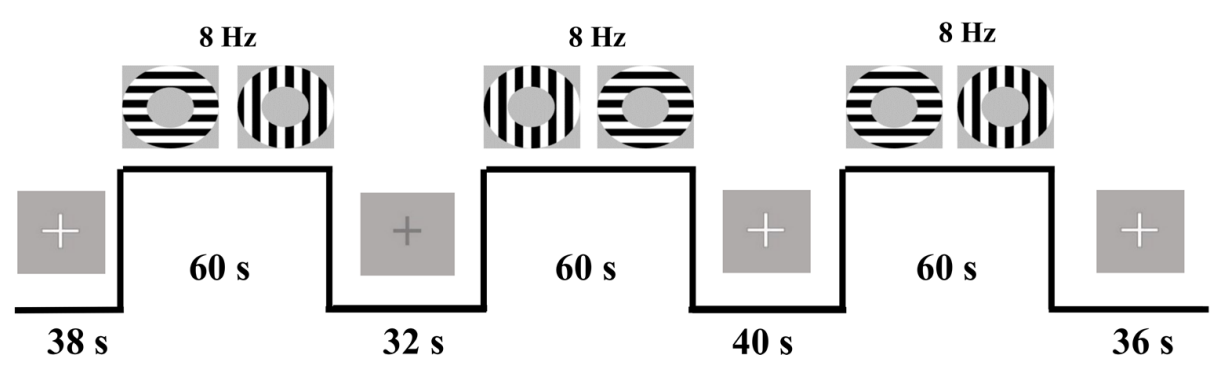

Figure 1. Example of three-trial visual stimulation task. Participants viewed a fixation cross at the center of the screen. This cross changed color at jittered intervals throughout task. Rest periods were also jittered. Continuous stimulation blocks lasted $60 \mathrm{~s}$ with $0^{\circ}$ to $90^{\circ}$ flickering annuli (at $8 \mathrm{~Hz}$ ). Note: fixation cross was presented during task and rest periods however it cannot be seen in the task example periods here.

Participants also completed a gas-challenge in order to estimate $M$. Participants breathed $4 \mathrm{~min}$ of room air $\left(\sim 0.03 \% \mathrm{CO}_{2}: 21 \% \mathrm{O}_{2}: 78 \% \mathrm{~N}_{2}\right)$ and 6 min of an iso-oxic, $\mathrm{CO}_{2}$ solution $\left(5 \% \mathrm{CO}_{2}: 21 \%\right.$ $\mathrm{O}_{2}: 74 \% \mathrm{~N}_{2}$ ) during dual-echo imaging. Each participant was fitted with a two-way, non-rebreathing valve/mouthpiece and a nose clip. Baseline end-tidal $\mathrm{CO}_{2}\left(\mathrm{EtCO}_{2}\right), \mathrm{O}_{2}$ saturation, breath rate, and heart rate measures were collected. After the $4 \mathrm{~min}$ of room air breathing, a valve was opened to release the $\mathrm{CO}_{2}$ solution from a Douglas airbag which then flowed into the participants' breathing apparatus [22,23]. The $\mathrm{CO}_{2}$ inhalation lasted 6 min.

Hypercapnic challenge, via the inhaled $5 \% \mathrm{CO}_{2}$ solution, increases global $\mathrm{CBF}$, but probably has no or a minimal depressant effect on oxygen metabolism, e.g., [61-63]. Hypercapnia acts to wash out local baseline concentrations of deoxyhemoglobin, yielding a local maximum estimate of resting BOLD 
signal. Potential changes to oxygen metabolism due hypercapnic challenge have not been shown to appreciably alter the estimation of $M$ as relationships between hypercapnia-derived $M$ and $M$ derived from non-hypercapnic techniques show high correspondence [64].

\section{5. cfMRI Processing}

Task and gas-challenge Echo 1 and Echo 2 data were processed in analysis of functional neuroimages (AFNI [65]) and the Functional MRI of the Brain Software Library (FSL [66]). Data were transformed into cardinal planes. Anomalous data points in each voxel time series were then attenuated using an interpolation method based upon the average signal. Data were volume registered to correct for motion to the fourth functional volume of each dataset's (task or gas challenge) Echo 2 sequence using a heptic polynomial interpolation method. CBF was estimated from Echo 1 images using the surround subtraction method [67]. Dual-echo BOLD data were also interpolated by pairwise averaging of temporally adjacent images.

For the visual stimulation task, Echo 2 data were linearly registered (12 degrees-of-freedom) to each participant's anatomical data using AFNI's align_epi_anay.py program. The transformation matrix from this registration was then applied to Echo 1 data, placing these two datasets in the same space. For gas-challenge data, a binary mask was created for functional voxels in Echo 2 to aid in co-registration. This mask was then registered to the respective participant's anatomical space using the align_epi_anay.py program. Gas-challenge Echo 2 and Echo 1 data were also aligned to the mask which was registered in native anatomical space. After alignment, Echoes 1 and 2 data from both the visual task and gas challenge were visually inspected for registration errors. One HC participant failed to register correctly after multiple attempts and was discarded from further analyses. Echoes 1 and 2 data from the visual task and gas challenge were then spatially smoothed using a Gaussian kernel $($ FWHM $=8 \mathrm{~mm})$ and high-pass filtered $(0.0039 \mathrm{~Hz})$.

Preprocessed data from Echoes 1 and 2 in the visual stimulation task were analyzed via generalized linear modeling of task versus rest periods using a boxcar reference function. This modeling quantified task-related CBF and BOLD changes from baseline. BOLD and CBF beta-values were scaled to each voxel's resting baseline signal and were multiplied by 100, yielding percent signal change estimates from baseline $(\triangle B O L D$ and $\triangle \mathrm{CBF})$. Data were averaged from a visual (functional) region of interest (ROI) comprised of overlapping $\triangle B O L D$ and $\triangle \mathrm{CBF}$ suprathreshold signals within occipital lobe (see Structural and Functional ROI; [22,23]). $\triangle B O L D, \triangle C B F, \triangle C M R O_{2}$, and $\mathrm{n}$ results extracted from the functional region of interest were taken as the visual-evoked signals (i.e., veBOLD, veCBF, veCMRO ${ }_{2}$, and ven).

For the gas challenge, resting baseline BOLD and CBF signals during room air breathing were averaged for each voxel time-series $\left(\mathrm{BOLD}_{0}\right.$ and $\left.\mathrm{CBF}_{0}\right)$. The first two minutes of hypercapnia BOLD and CBF time-series were discarded to allow participants' blood flow to stabilize on the $\mathrm{CO}_{2}$ solution, e.g., [22,23]. The last four minutes of hypercapnia BOLD and CBF time-series were averaged to yield $B O L D_{h c}$ and $C_{B F}$ respectively. Average values were extracted from a functional region of interest (see Structural and Functional ROI) using overlapping $\mathrm{BOLD}_{\mathrm{hc}}$ and $\mathrm{CBF}_{\mathrm{hc}}$ suprathreshold signals within occipital lobe, and were used to calculate $M$, using the following equation:

$$
M=\frac{\frac{\mathrm{BOLD}_{\mathrm{hc}}-\mathrm{BOLD}_{0}}{\mathrm{BOLD}_{0}}}{\left(1-\left(1+\frac{\mathrm{CBF}_{\mathrm{hc}}-\mathrm{CBF}_{0}}{\mathrm{CBF}_{0}}\right)^{\alpha-\beta}\right)}
$$

where $\left(\mathrm{x}_{\mathrm{hc}}-\mathrm{x}_{0}\right) / \mathrm{x}_{0}$ reflects percent change in signal from normocapnic to hypercapnic states, normalized by the signals during normocapnia and multiplied by 100 . Once $M$ was estimated, $\Delta \mathrm{CMRO}_{2}$ and $n$ were also estimated (see Equations (2) and (3); see Figure 2) within a functional region of interest (see Structural and Functional ROI). 


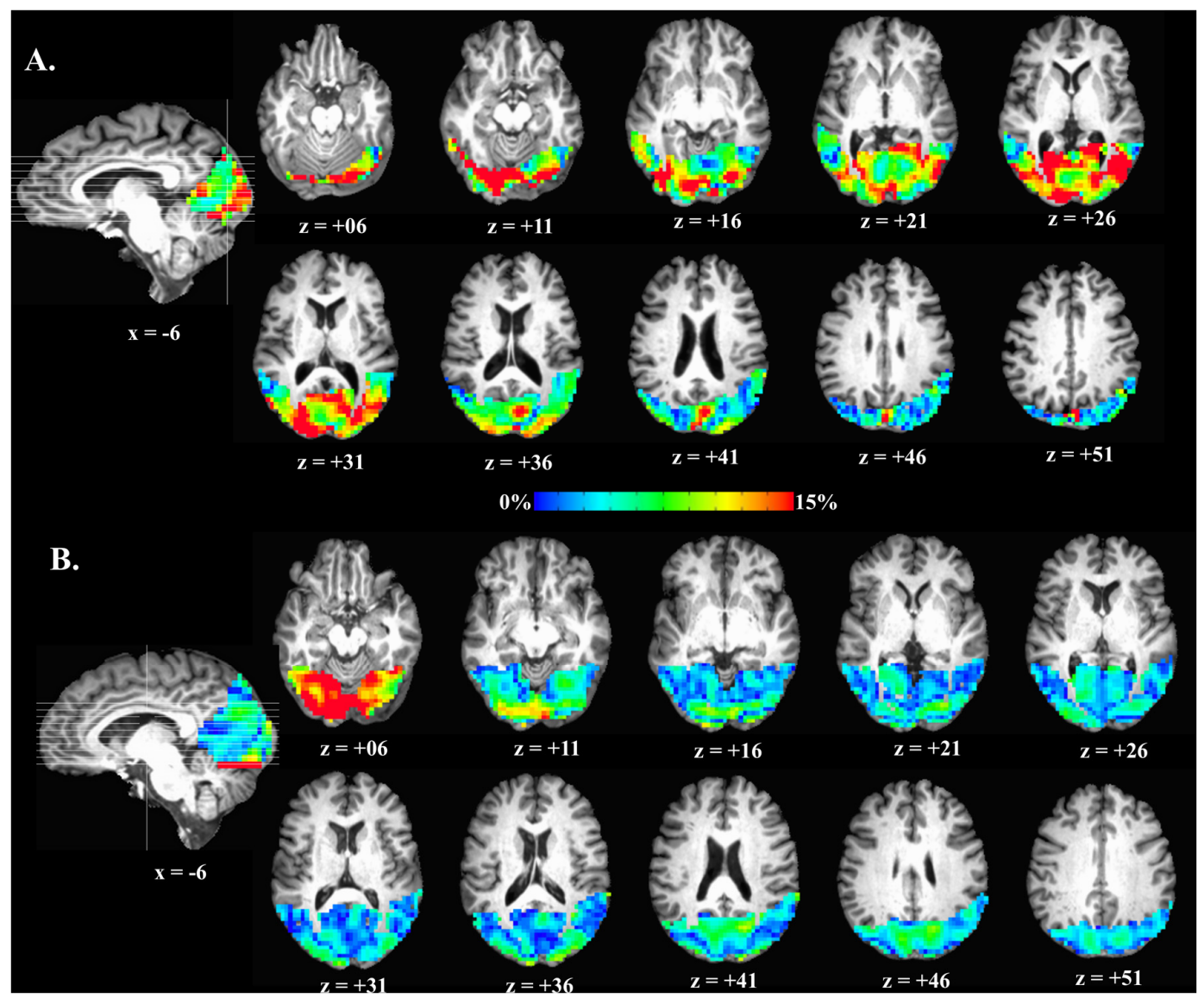

Figure 2. Examples of oxygen metabolism changes $\left(\triangle \mathrm{CMRO}_{2}\right)$ in occipital lobe. (A) $\mathrm{HC} \Delta \mathrm{CMRO}_{2}$; (B) MS patient $\Delta \mathrm{CMRO}_{2} \cdot \mathrm{x}=$ right-left, $\mathrm{z}=$ superior-inferior.

\subsection{Structural and Functional ROIs}

First, the magnetization-prepared rapid acquisition gradient-echo (MPRAGE) data were processed to create a native-space, occipital ROI. The skull was removed using an automated command, separating parenchyma and cerebral spinal fluid from the skull. An intensity based automated segmentation algorithm was used to delineate primarily white matter, grey matter, and cerebral spinal fluid voxels yielding a partial volume estimate of each tissue type, for each voxel. A grey matter mask was then created, retaining voxels with only a greater than or equal to grey matter partial volume estimate of $80 \%$. A structural ROI of occipital lobe was manually delineated on each participant's MPRAGE image. These were drawn in native space because native space analyses tend to allow for more sensitive patient-control contrasts [68]. The structural ROI was drawn using gyral and sulcal landmarks and encompassed most of occipital cortex including calcarine sulcus, cuneus, and occipital portions of lingual gyrus. Several anatomical landmarks were used in the demarcation of this ROI (parieto-occipital sulcus, occipital pole, pre-occipital notch). Within the anatomically defined occipital lobe, only voxels with partial volume estimates of grey matter $(\geq 80 \%)$ were retained. These final masks were down-sampled to the functional voxel size.

A visual task functional ROI was created within the structural ROI described above to estimate veBOLD, veCBF, veCMRO $\mathrm{C}_{2}$, and ven (see Figure 3). This procedure eschewed noise from inactive voxels, e.g., [68]. Voxels comprising each participant's functional ROI were the overlapping top 5\% of BOLD and top 5\% of CBF $t$-values obtained from the generalized model, within the structural ROI. This ensured that average veBOLD and veCBF estimates were being derived from the same, task-responsive voxels and that veCMRO 2 and ven were derived in voxels with both CBF and BOLD task-related increases (see Figure 3). 


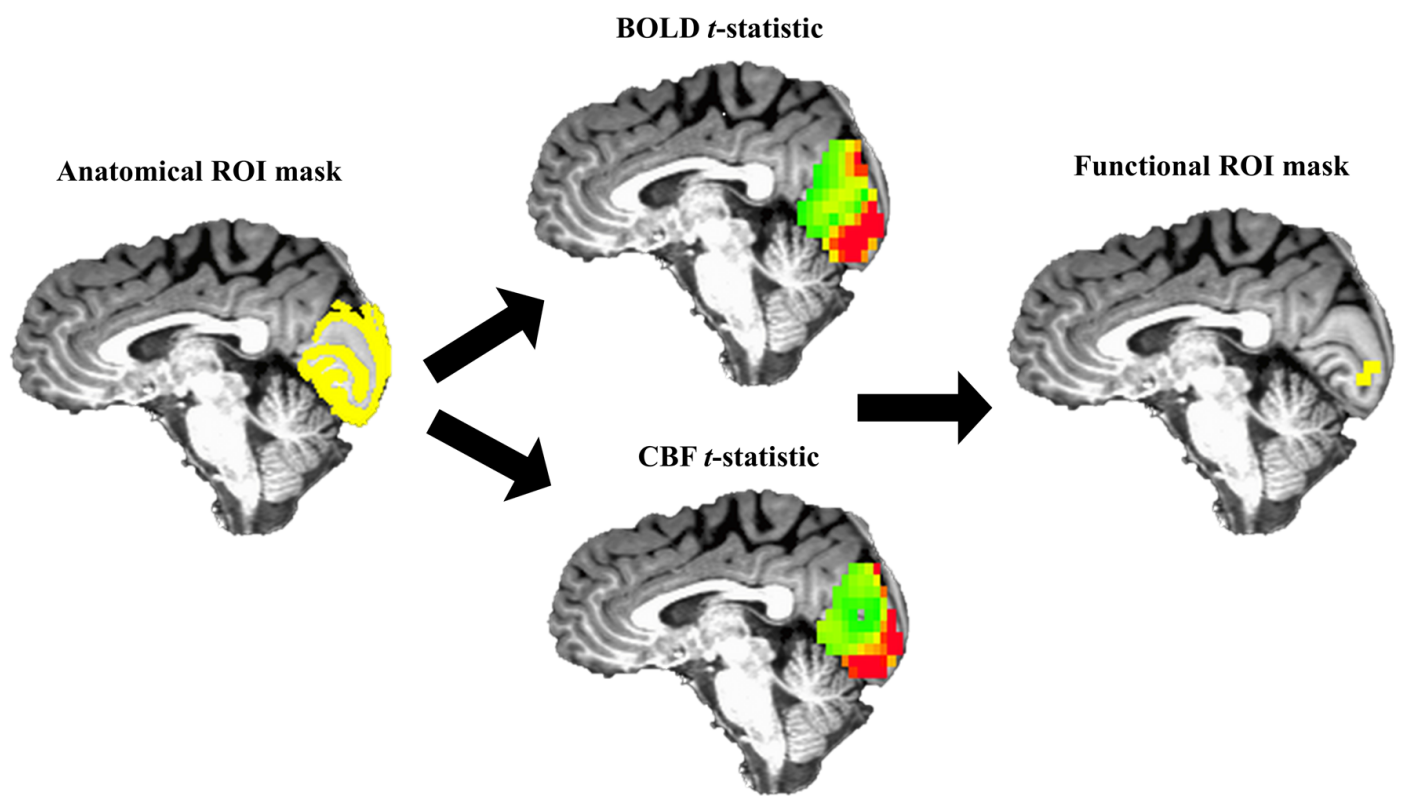

Figure 3. Graphical overview of masking procedure. For each participant, their top $5 \%$, overlapping BOLD and CBF $t$-statistics (middle) within the anatomical ROI (left, yellow) were used to create the functional ROI mask (right, yellow). Functional measures (veBOLD, veCBF, veCMRO 2 , and ven) were extracted from each participant's functional ROI mask.

veCMRO 2 was calculated voxel-wise within the functional ROI using $\triangle B O L D, \triangle C B F$, $M$ (which was extracted from functional ROI described below). ven was then calculated similarly. The final product of these analyses was average positive veBOLD, veCBF, and veCMRO extracted from the functional ROI (see Figure 3).

Because the gas challenge data differed in occipital coverage compared to the visual task data, $M$ was estimated ex situ. To create a functional ROI for the gas challenge, $\triangle B O L D_{h c} / B O L D_{0}$ and $\triangle \mathrm{CBF}_{\mathrm{hc}} / \mathrm{CBF}_{0}$ maps were thresholded and extracted from the structural ROI detailed above. The criteria for retention of a voxel within these maps required that the voxel was within the top $15 \%$ (top $20 \%$ for one participant) of $\triangle \mathrm{BOLD}_{\mathrm{hc}} / \mathrm{BOLD}_{0}$ and $\triangle \mathrm{CBF}_{\mathrm{hc}} / \mathrm{CBF}_{0}$ voxels in the structural ROI, and that these $\triangle B O L D_{h c} / B O L D_{0}$ and $\triangle C B F_{h c} / C_{B F}$ voxels overlapped. This procedure ensured complementary maximum $\triangle B O L D_{h c} / B O L D_{0}$ and $\triangle C B F_{h c} / C B F_{0}$ signals in the retained voxels. Average $\triangle B O L D_{h c} / B O L D_{0}$ and $\triangle \mathrm{CBF}_{\mathrm{hc}} / \mathrm{CBF}_{0}$ signals were extracted from this $\mathrm{ROI}$ and $M$ was calculated (see Equation (4)).

\subsection{Structural Images}

One $\mathrm{T}_{1}$-weighted MPRAGE image was acquired for each participant: 160 slices, $\mathrm{TE}=3.7 \mathrm{~ms}$, repetition time TR $=8.1 \mathrm{~ms}$, sagittal slice orientation, $1 \times 1 \times 1 \mathrm{~mm}^{3}$ voxel, $12^{\circ}$ flip angle. SIENAX $[15,69]$ was used to obtain measures of grey matter, white matter, and total brain volume normalized by participant's head size. This technique uses partial volume estimation to calculate volume of differing tissue types (see Figure 4B,C). Further, this technique takes into account lesioned tissue, as demarcated by lesion masks (see below), in order to avoid misclassification of this tissue. The final products of these analyses were scaled estimates of each participant's grey matter, white matter, and total brain volume $\left(\mathrm{mm}^{3}\right)$.

$\mathrm{A} \mathrm{T}_{2}$ fluid attenuated inversion recovery (FLAIR) scan was also acquired for each participant: 33 slices, $\mathrm{TE}=125 \mathrm{~ms}, \mathrm{TR}=11,000 \mathrm{~ms}$, no slice gap, transverse slice orientation, $0.45 \times 0.45 \times 5.00 \mathrm{~mm}^{3}$ voxel, $120^{\circ}$ refocusing angle. FLAIR images were used to estimate the extent of gross lesion burden for each participant. Hyperintense voxels were demarcated using in-house MATLAB code based upon slice-wise, signal intensity (i.e., voxels that were $\geq 1.25 \mathrm{SD}$ over the slice mean intensity). 
Next, lesions were manually delineated from the hyperintense tissue by two trained researchers (L.H., S.F.). Manual delineation ruled out false positives in lesion classification due to fat signals, motion, ventricular edge effects, skull, or signal inhomogeneites [70]. Lesion burden was estimated by extracting the number of voxels that were demarcated by the automated and manual procedures. Inter-rater agreement of lesion burden was calculated using a Dice ratio $(\kappa)$ of the lesion burden estimates made by the two researchers on a sample of several subjects [71]. After the researchers were trained on lesion classification, inter-rater agreement was found to be high, $k=0.89$; where $k>0.70$ is generally thought to reflect excellent inter-rater agreement [72]. Lesion burden was quantified using absolute (total $\mathrm{mm}^{3}$ of lesioned tissue; see Figure 4E) and relative scales (percent of total $\mathrm{mm}^{3}$ of lesioned tissue scaled by uncorrected white matter volume in $\mathrm{mm}^{3}$ ). Spatially distinct lesion count was also obtained by counting the number of non-touching lesions for each subject (see Figure 4F), e.g., [73]. A lesion was required to have at least $3 \mathrm{~mm}^{3}$ volume in order to be added to the total lesion count. Thus, the final products of these analyses were absolute lesion volume, relative lesion volume, and spatially distinct lesion count.

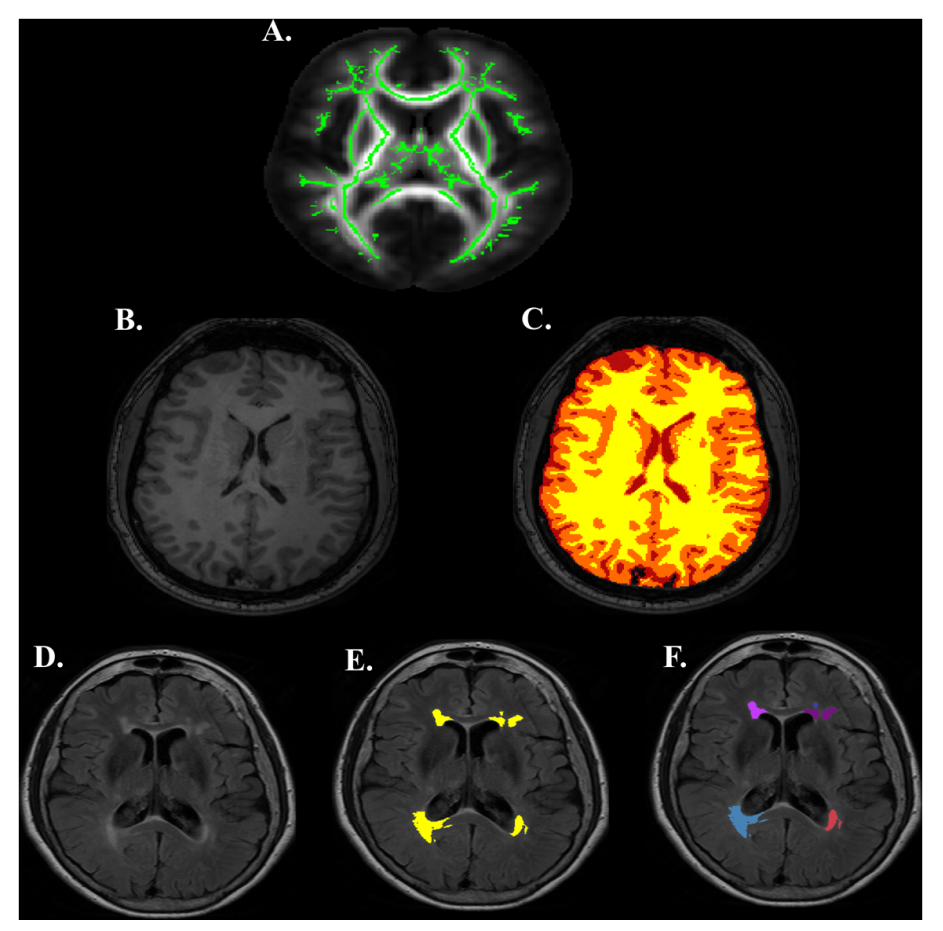

Figure 4. Diffusion and Structural Image Processing Examples. (A) Diffusion tensor imaging white matter skeleton. (B) $\mathrm{T}_{1}$ image. (C) $\mathrm{T}_{1}$ image segmented into white matter (yellow), grey matter (orange), and cerebral spinal fluid (red) using SIENAX. (D) $\mathrm{T}_{2}$-FLAIR image. (E) Lesions demarcated (yellow) on $\mathrm{T}_{2}$-FLAIR image used for calculating lesion burden. (F) Spatially distinct lesions demarcated on $\mathrm{T}_{2}$-FLAIR image.

\subsection{Diffusion Images}

DTI images were acquired using a single-shot, echo-planar imaging sequence with a Sensitivity Encoding parallel imaging scheme (reduction factor $=2.3$ ), $112 \times 112$ matrix, field of view $=224 \times 224 \mathrm{~mm}^{2}$ (nominal resolution of $2 \mathrm{~mm}$ ), 65 slices $(0 \mathrm{~mm}$ gap), slice thickness $=2 \mathrm{~mm}, \mathrm{TR}=7.78 \mathrm{~s}, \mathrm{TE}=97 \mathrm{~ms}$. The diffusion weighting was encoded along 30 independent orientations [74] and the $b$ value was $1000 \mathrm{~s} / \mathrm{mm}^{2}$. Imaging time was $5 \mathrm{~min}$ and $15 \mathrm{~s}$. Two HCs did not undergo DTI ( $\left.n \mathrm{HC}=11\right)$.

Automatic Image Registration [75] was performed on raw diffusion-weighted images to correct distortion caused by eddy currents. Six elements of the $3 \times 3$ diffusion tensor were determined by multivariate least-squares fitting. The tensor was diagonalized to obtain three eigenvalues $\left(\lambda_{1-3}\right)$ 
and eigenvectors $\left(\mathrm{v}_{1-3}\right)$. Standard tensor fitting was conducted with DTIStudio [76] to generate the most common DTI-derived diffusion characteristics, fractional anisotropy (FA), axial diffusivity (AD), mean diffusivity (MD), and radial diffusivity (RD).

DTI measurements were obtained at the skeletons of the white matter using FSL [77] to alleviate partial volume effects with tract-based spatial statistics (see Figure $4 \mathrm{~F}-\mathrm{H}$ ) [77]. Participant FA maps were registered nonlinearly to the EVE single-subject FA template [78-80] for better alignment with a digital white matter atlas (JHU ICBM-DTI-81) [81]. Registered FA maps of all subjects were averaged to generate a mean FA map, from which an FA skeleton mask was created. Skeletonized FA images of all subjects were obtained by projecting the registered FA images onto the mean FA skeleton mask. Skeletonized $\mathrm{AD}, \mathrm{MD}$, and $\mathrm{RD}$ metrics were obtained by applying the same registration, projection, and skeletonization procedures. We extracted skeleton-wide averages of each DTI metric (i.e., AD, FA, $\mathrm{MD}, \mathrm{RD}$ ), wherein an average of each metric is calculated across all voxels within the white matter skeleton (see Figure 4A).

\subsection{Statistical Analyses}

All analyses were performed on distributions free of outliers $(\geq \pm 2$ SD from group mean for simple group comparisons, $\geq \pm 3$ MAD from group median for classification modeling see [82]). Binary logistic regression was used for classifying MS status. A description of model variables can be found in Table 2 . The accuracies of these models were computed as the proportion of correct classification outcomes over all outcomes. Accuracy was chosen as the metric of interest because it combines sensitivity and specificity in binary classification analysis by taking into account both true positives and true negatives relative to all outcomes. We used resampling-based hypothesis testing to examine both within-sample and out-of-sample classification of patient status see [83]. Because we used relatively conservative analytic techniques, inherently reducing the likelihood of Type I error and increasing the generalizability of our results, the criterion for a rejection of the null hypothesis was not corrected for multiple comparisons and all models were evaluated at the field-standard $\alpha=0.05$. We also denote which hypothesis tests survived Benjamini-Hotchberg correction (Table 4; Figure 7).

Within-sample classification analyses obtained bias-corrected and accelerated (BCa) bootstrappedresampled $(B=10,000) 95 \%$ confidence intervals of the accuracy of binary logistic regression models. The BCa procedure was used because it is robust to both skewness and sampling bias in the bootstrap distribution [84]. To avoid unstable classification, we stratified all resamples to match the original sample's constitution of patients and controls, $56.5 \%$ and $43.5 \%$, respectively. If the BCa-derived $95 \%$ confidence interval did not contain a value at or below 0.50 (binary chance), this would demonstrate the measure's accuracy was significantly greater than chance to classify MS patients and HCs.

Out-of-sample classification analyses used a leave-one-out cross-validation approach [85]. This technique used training and sample iterations to test the ability of the model derived from the training set to predict an observation in the test (out-of-sample) set, thus, circumventing problems of sample bias, model over fitting, and lending a true predictive element to these analyses. Briefly, the leave-one-out cross validation (LOOCV) approach fitted $\mathrm{N}$ models, where $\mathrm{N}$ was proportional to our sample size. Each model was trained on $\mathrm{N}-1$ samples and then the accuracy of the training model was assessed on the left-out sample. The $\mathrm{N}$ accuracies were then averaged to attain a representative and generalizable measure of the average out-of-sample classification accuracy. Permutation based $p$-values (5000 permutations) were computed to assess the significance of the LOOCV-derived accuracy statistics. The test permuted patient status labels and recomputed the accuracy of the model at each iteration, thus building the null distribution. The $p$-values were calculated from the percentage of the accuracy estimates of the permuted samples that were better than actual LOOCV-derived accuracy statistic of each model. This procedure was slightly modified according to Ojala and Garriga [86]. 


\section{Results}

\subsection{Visual Task Performance}

MS patients $(92.75 \pm 1.11 \%)$ did not significantly differ from HCs $(94.86 \pm 0.44 \%)$ on accuracy on the visual stimulation secondary task, $t(10.54)=-1.76, p=0.108$. Patients $(492.06 \mathrm{~ms} \pm 31.15)$ also did not significantly differ from HCs (487.19 $\mathrm{ms} \pm 24.10)$ on their average correct response time to press the button on the secondary task, $t(16.22)=0.12, p=0.903$.

\subsection{Group Physiology, Cerebrovascular Response to Gas Challenge, and M}

MS and $\mathrm{HCs}$ did not significantly differ in breath rate, end-tidal $\mathrm{CO}_{2}$, heart rate, or $\mathrm{O}_{2}$ saturation at baseline or during $\mathrm{CO}_{2}$ solution breathing (all ps $>0.05$; see Table 3 ). We tested whether MS patients differed in their $\mathrm{CBF}$ response to the $\mathrm{CO}_{2}$ solution $\left(\left(\mathrm{CBF}_{\mathrm{hc}}-\mathrm{CBF}_{0}\right) / \mathrm{CBF}_{0}\right)$ and $M$ in their respective gas challenge ROIs within occipital lobe see [87]. MS patients did not significantly differ in CBF response to the $\mathrm{CO}_{2}$ solution $(167.48 \pm 19.8 \%)$ compared to $\mathrm{HCs}(146.90 \pm 14.64 \%), t(15.70)=0.83$, $p=0.417$. MS patients $(3.88 \pm 0.48 \%)$ did not significantly differ in M compared to HCs $(5.11 \pm 0.39 \%)$, $t(18.90)=-1.98, p=0.062$.

Table 3. Sample Physiological Data.

\begin{tabular}{llll}
\hline & MS & HC & $p$ \\
\hline Baseline & & & \\
\hline Breath Rate & $11.20(1.00)$ & $10.25(0.79)$ & $0.747^{\mathrm{a}}$ \\
$\mathrm{EtCO}_{2}$ & $42.70(1.81)$ & $39.23(0.74)$ & $0.101^{\mathrm{b}}$ \\
$\mathrm{Heart} \mathrm{Rate}$ & $66.90(2.38)$ & $72.08(3.18)$ & $0.207^{\mathrm{b}}$ \\
$\mathrm{SpO}_{2}$ & $98.10 \%(0.35 \%)$ & $97.85 \%(0.32 \%)$ & $0.596^{\mathrm{b}}$ \\
\hline $5 \% \mathrm{CO}_{2}$ & & & \\
\hline $\mathrm{Breath}$ Rate & $13.35(1.28)$ & $15.42(1.07)$ & $0.236^{\mathrm{c}}$ \\
$\mathrm{EtCO}_{2}$ & $48.95(1.45)$ & $49.06(0.64)$ & $0.950^{\mathrm{c}}$ \\
$\mathrm{Heart} \mathrm{Rate}$ & $69.67(2.38)$ & $75.04(2.60)$ & $0.147^{\mathrm{d}}$ \\
$\mathrm{SpO}_{2}$ & $97.58 \%(0.39 \%)$ & $98.20 \%(0.20 \%)$ & $0.139^{\mathrm{d}}$ \\
\hline
\end{tabular}

Mean (SEM). Breath Rate in breaths per minute. $\mathrm{EtCO}_{2}=$ end-tidal $\mathrm{CO}_{2}$ in $\mathrm{mmHg}$. Heart Rate in beats per minute. $\mathrm{SpO}_{2}=$ peripheral oxygen saturation in percent hemoglobin saturation. $p$-values were based on independent samples. ${ }^{a} 22$ degrees-of-freedom; ${ }^{\mathrm{b}} 21$ degrees-of-freedom; ${ }^{\mathrm{c}} 16$ degrees-of-freedom; ${ }^{\mathrm{d}} 17$ degrees-of-freedom.

\subsection{Group Comparisons on Visual Task cfMRI Measures}

MS patients $(1.12 \pm 0.77 \%)$ did not significantly differ from HCs $(1.18 \pm 0.66 \%)$ on veBOLD response to visual stimulation, $t(19.18)=-0.60, p=0.555$. MS patients $(4.08 \pm 0.35)$ did not show significant changes in ven compared to HCs $(4.23 \pm 0.23), t(16.16)=-0.35, p=0.731$. MS patients (48.06 $\pm 12.58 \%$ ) had significant decreases in veCBF compared to HCs $(92.68 \pm 17.29 \%)$, $t(19.76)=-2.09, p=0.050$. MS patients $(9.59 \pm 0.90 \%)$ also showed significant decreases in veCMRO compared to HCs $(17.85 \pm 1.97 \%), t(16.45)=-3.81, p=0.002$ (see Figure 5).

\subsection{Within-Sample Classification Analyses}

Measures are ranked on original accuracy and presented in Table 4. Accuracy and smoothed density distributions for the significant and bottom 5 measures can be found in Figure 6 .

\subsection{Out-of-Sample Classification Analyses}

Predictors presented in Figure 7 are ranked on LOOCV-derived accuracy. 


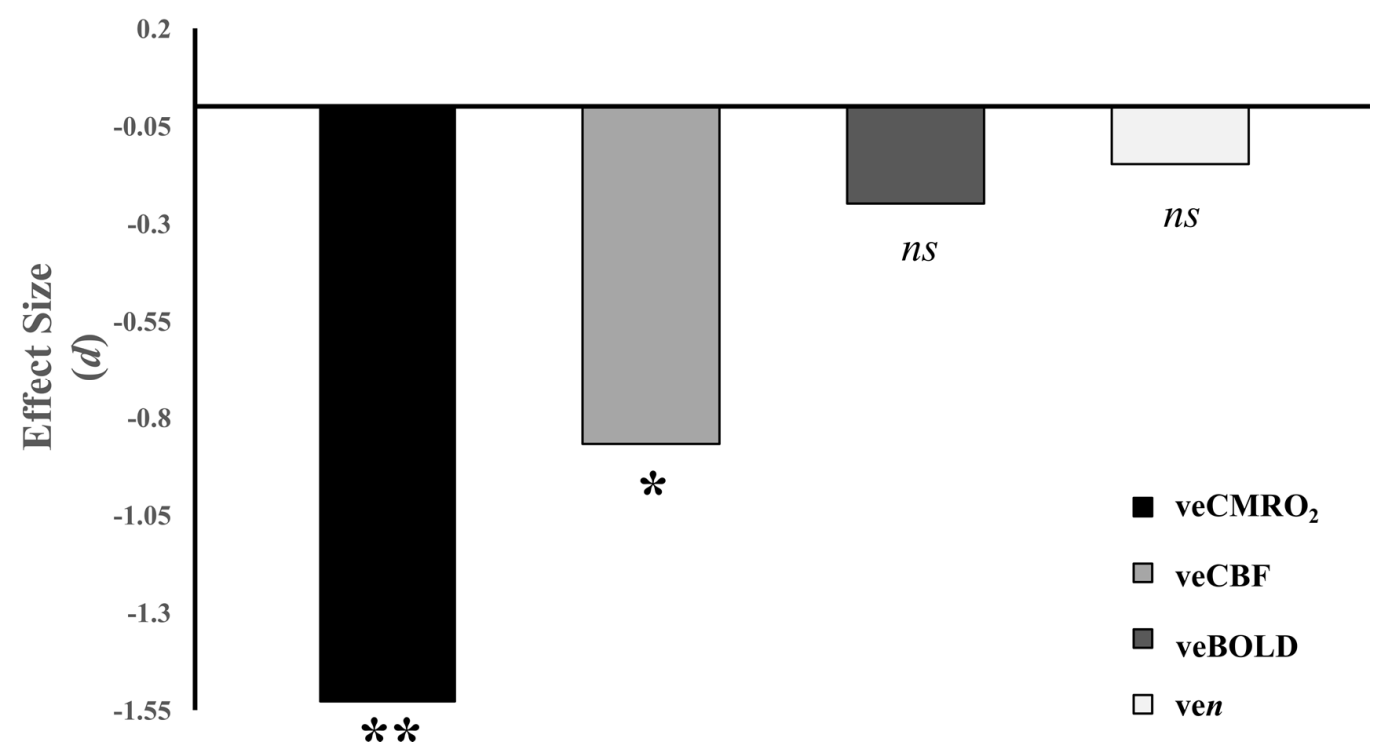

Figure 5. Effect sizes of group contrasts on calibrated functional magnetic imaging measures. Effect sizes reflect Cohen's $d$. ns = non-significant effect, $p>0.05 ;{ }^{*} p<0.05 ;{ }^{* *} p<0.01$.

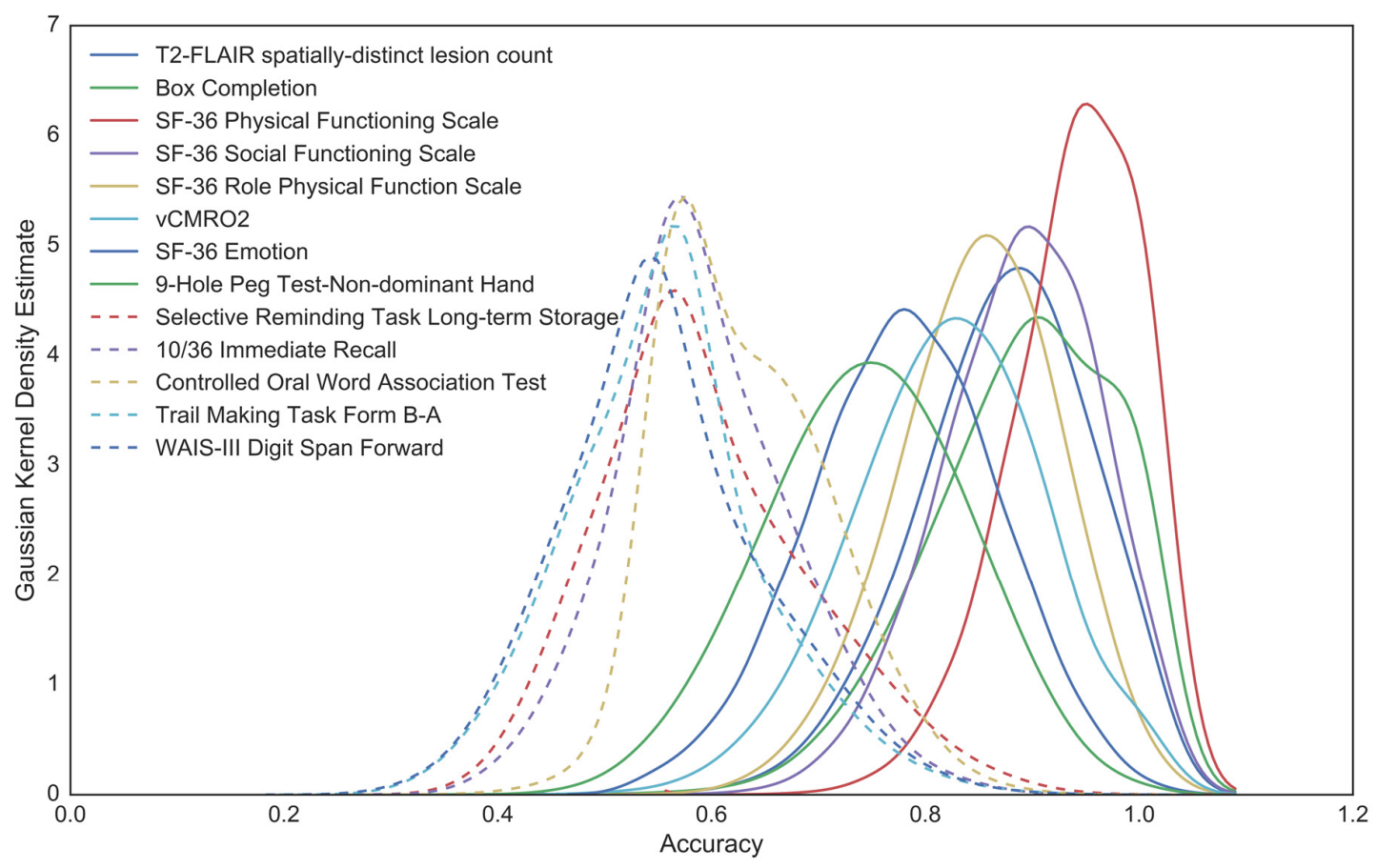

Figure 6. Smoothed density estimates of BCa-bootstap distributions. Distributions of significant (solid lines) and bottom 5 (dashed lines) within-sample predictors of MS status are illustrated. Note: because of smoothing, tails of distributions may exceed 1. 
Table 4. Accuracy and 95\% Confidence Limits of Within-Sample Classification Analyses.

\begin{tabular}{|c|c|c|c|c|}
\hline Predictor & Predictor Accuracy & 95\% LCL & $95 \%$ UCL & Significant \\
\hline SF-36 Physical Functioning Scale & 0.94 & 0.65 & 1.00 & Yes + \\
\hline SF-36 Social Functioning Scale & 0.89 & 0.61 & 0.94 & Yes + \\
\hline $\mathrm{T}_{2}$-FLAIR spatially distinct lesion count & 0.86 & 0.57 & 0.95 & Yes + \\
\hline Box Completion & 0.86 & 0.52 & 0.95 & Yes + \\
\hline SF-36 Role Physical Function Scale & 0.85 & 0.60 & 0.95 & Yes + \\
\hline veCMRO ${ }_{2}$ & 0.82 & 0.55 & 0.91 & Yes $\ddagger$ \\
\hline Normalized Grey Matter Volume & 0.81 & 0.43 & 0.95 & No $\ddagger$ \\
\hline $\mathrm{T}_{2}$-FLAIR Lesion Burden-absolute lesion volume & 0.80 & 0.50 & 0.90 & No $\ddagger$ \\
\hline $\mathrm{T}_{2}$-FLAIR Lesion Burden-relative lesion volume & 0.80 & 0.50 & 0.90 & No $\ddagger$ \\
\hline SF-36 Emotion & 0.78 & 0.56 & 0.89 & Yes \\
\hline 9-Hole Peg Test-Non-dominant Hand & 0.77 & 0.55 & 0.91 & Yes $\ddagger$ \\
\hline SF-36 General Health Scale & 0.77 & 0.50 & 0.86 & No $\ddagger$ \\
\hline veCBF & 0.75 & 0.45 & 0.85 & No $\ddagger$ \\
\hline Normalized Whole Brain Volume & 0.73 & 0.45 & 0.86 & No \\
\hline 9-Hole Peg Test-Dominant Hand & 0.73 & 0.50 & 0.82 & No \\
\hline SF-36 Bodily Pain Scale & 0.73 & 0.45 & 0.86 & No \\
\hline Skeleton AD & 0.71 & 0.43 & 0.81 & No \\
\hline Skeleton MD & 0.71 & 0.48 & 0.86 & No \\
\hline Paced Auditory Serial Addition Test $2 \mathrm{~s}$ & 0.71 & 0.48 & 0.86 & No \\
\hline Modified Fatigue Impact Score Total & 0.70 & 0.43 & 0.78 & No $\ddagger$ \\
\hline Normalized White Matter Volume & 0.68 & 0.45 & 0.82 & No \\
\hline Paced Auditory Serial Addition Test $3 \mathrm{~s}$ & 0.68 & 0.45 & 0.82 & No \\
\hline Skeleton RD & 0.67 & 0.48 & 0.76 & No \\
\hline Trail Making Task Form A & 0.65 & 0.43 & 0.78 & No \\
\hline SF-36 Vitality Scale & 0.65 & 0.43 & 0.74 & No \\
\hline 25 Foot Walk & 0.64 & 0.50 & 0.77 & No \\
\hline WAIS-III Digit Span Backward & 0.64 & 0.41 & 0.77 & No \\
\hline WAIS-III Digit Span Total & 0.64 & 0.41 & 0.82 & No \\
\hline 10/36 Delayed Recall & 0.63 & 0.42 & 0.74 & No \\
\hline Trail Making Task Form B & 0.62 & 0.33 & 0.76 & No \\
\hline SF-36 Mental Health Scale & 0.62 & 0.38 & 0.62 & No \\
\hline veBOLD & 0.61 & 0.48 & 0.78 & No \\
\hline Selective Reminding Task Delayed & 0.60 & 0.35 & 0.60 & No \\
\hline Symbol-digit Modalities Test & 0.60 & 0.30 & 0.70 & No \\
\hline Number Comparison & 0.59 & 0.36 & 0.68 & No \\
\hline WAIS-III Digit symbol coding & 0.58 & 0.37 & 0.58 & No \\
\hline Skeleton FA & 0.57 & 0.37 & 0.67 & No \\
\hline ven & 0.57 & 0.39 & 0.52 & No \\
\hline Selective Reminding Task Long-term Storage & 0.57 & 0.35 & 0.70 & No \\
\hline Controlled Oral Word Association Test & 0.57 & 0.35 & 0.57 & No \\
\hline 10/36 Immediate Recall & 0.52 & 0.30 & 0.57 & No \\
\hline WAIS-III Digit Span Forward & 0.50 & 0.27 & 0.55 & No \\
\hline Trail Making Task Form B-A & 0.48 & 0.29 & 0.52 & No \\
\hline
\end{tabular}

$\mathrm{LCL}=$ lower confidence limit. $\mathrm{UCL}=$ upper confidence limit. Confidence limits based upon 10,000 iteration BCa-corrected bootstrapping procedure. Yes $=95 \%$ confidence interval $(\mathrm{CI})$ does not contain $0.50 ; \mathrm{No}=95 \% \mathrm{CI}$ contains 0.50 . Note: that the original parameter estimates do not necessarily need to lie within the $95 \% \mathrm{CI}$ of the BCa-corrected, empirically derived distributions. † permutation $p$-value significant using Benjamini-Hotchberg correction $(p<0.05)$. $\ddagger$ permutation $p$-value marginally significant using Benjamini-Hotchberg correction $(p<0.10)$. 


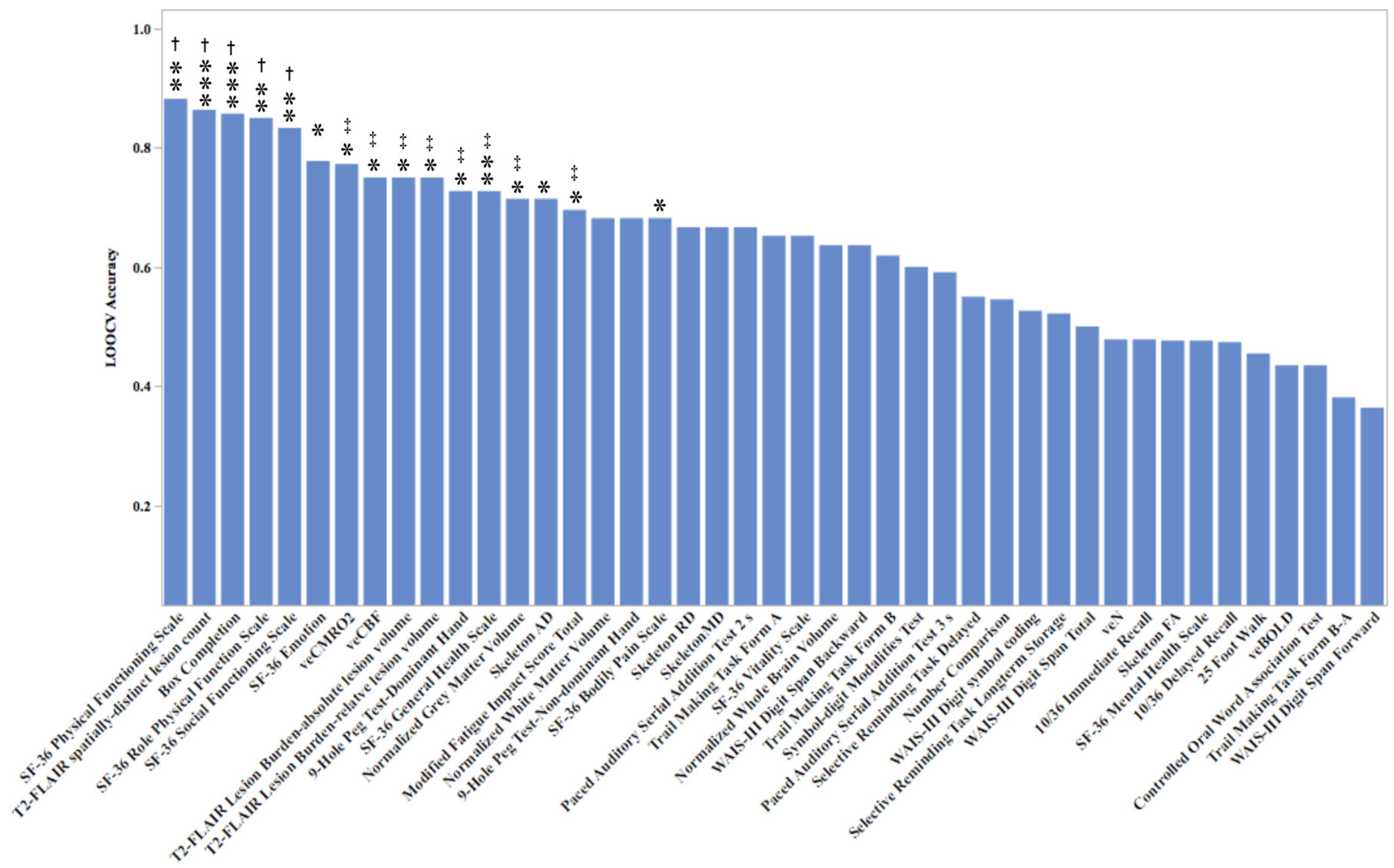

Figure 7. Leave-one-out cross-validation (LOOCV) out-of-sample classification accuracy of each model. ${ }^{*} p<0.05 ;{ }^{* *}=p<0.01 ;{ }^{* * *}=p<0.001$. $+p$-value also significant using Benjamini-Hotchberg correction $(p<0.05)$. $\neq p$-value marginally significant using Benjamini-Hotchberg correction $(p<0.10)$. 


\section{Discussion}

In the present study, we used a neuroimaging approach novel to MS research (cfMRI) to assess the accuracy of veCMRO $\mathrm{O}_{2}$ in classifying MS patients and closely age- and sex-matched HC participants. MS patients showed similar responses to HCs in veBOLD and ven, however showed decreased veCBF and a pronounced decrease in veCMRO ${ }_{2}$ relative to HCs. Groups were similar on visual task performance and on physiological measures pertaining to the $\mathrm{CO}_{2}$ challenge, indicating that potential MS-related changes in physiological response to carbon dioxide, e.g., [87] or visual attention were not likely contributors to group $\mathrm{CMRO}_{2}$ differences. Within-sample classification analyses demonstrated that veCMRO ${ }_{2}$ was significant and one of the top measures to accurately classify MS status, discriminating between MS patients and HCs with exceptional accuracy (82\%). Results also showed that within-sample classification accuracy by veCMRO $\mathrm{Nas}_{2}$ wamparable to neuroimaging measures often used to gauge MS pathology, such as $\mathrm{T}_{2}$-FLAIR lesion burden ( $80 \%$ accuracy) and $\mathrm{T}_{1}$ grey matter volume ( $81 \%$ accuracy). veCMRO $\mathrm{O}_{2}$ was also significantly accurate in MS classification using out-of-sample observations (77\% accuracy). The use of such out-of-sample modeling afforded a predictive element to this study and demonstrated that veCMRO $\mathrm{N}_{2}$ can accurately classify new observations of MS and HC participants, offering support for its potential diagnostic utility.

One question that arises from these results is whether veCMRO $\mathrm{M}_{2}$ can add predictive value over other advanced imaging techniques not studied here. For instance, measurements of multifocal visual-evoked potentials have been of great interest to the MS research community. This technique, which uses visual stimulation and electroencephalogram signals in occipital channels proximal to the inion has been demonstrated to (1) more sensitively and specifically detect visual abnormalities in MS eyes relative to other visual-system measurements [88], (2) predict conversion to an MS diagnosis in persons with optic neuritis [89], and (3) relate to the extent of MS-related damage to visual white matter tracts [41]. Not surprisingly, this technique can also accurately discriminate between MS patients and HCs, e.g., [90]. For example, one study showed that measurements gathered from multifocal visual-evoked potentials were on average $74.76 \%$ accurate (range: $62.7 \%-96.1 \%$ ) in classifying within-sample observations of MS patients without optic neuritis and HCs ([90], average calculated from Figures 5 and 6, pp. 910-911). We can compare these figures with the within-sample accuracy of veCMRO ${ }_{2}$ observed here ( $\left.82 \%\right)$. This suggests that veCMRO $\mathrm{N}_{2}$ accuracy is in about the same range as multifocal evoked potentials. However, it performs appreciably better than the average multifocal evoked potential measure. Future research directly comparing veCMRO${ }_{2}$ to electroencephalogram and other measures is necessary to more faithfully adjudicate claims about the relative performance of this technique.

A second avenue for future research could involve examining whether the integration of evoked $\mathrm{CMRO}_{2}$ from other neural systems could maximize MS classification accuracy. Here, we showed significant decreases in MS patients' veCMRO $\mathrm{M}_{2}$ relative to $\mathrm{HCs}$. This variable was also largely accurate in the prediction of MS status. We looked at veCMRO $\mathrm{M}_{2}$ specifically because of robust alterations to the visual system in MS see [37-40]. However, because (1) mitochondrial alterations are found in multiple forms of neural tissue in MS [31,33] and (2) global brain decreases in oxygen metabolism have been found in MS patients relative to HCs [30], it is likely that evoked $\mathrm{CMRO}_{2}$ is affected in other neural systems as well. Our work and others' have shown altered patterns of brain activity in MS patients in motor, e.g., [42,91,92] and association cortices [43,93-95], see [96]. It is possible that the addition of measures of evoked $\mathrm{CMRO}_{2}$ in these areas could lend improvements in the accuracy of MS classification. One advantage of the cfMRI approach over other advanced imaging approaches in MS, like OCT or visual-evoked potentials, is that this technique can specifically and simultaneously assay multiple neural systems. Work underway in our laboratories is examining the extent to which evoked motor and executive system $\mathrm{CMRO}_{2}$ differs between MS patients and age- and sex-matched healthy $\mathrm{HCs}$, and whether these changes, along with veCMRO models of MS. 
The utility of imaging biomarkers in MS is not limited to assisting in diagnosis see [97]. For instance, OCT measures have been shown to be effective in predicting brain atrophy and visual acuity loss in MS see [38]. The retinal nerve fiber thickness and macular volume measures from OCT might also be useful in differentiating different subtypes of MS [98]. Other imaging-based measures, such as $\mathrm{T}_{2}$-lesion burden, have shown prognostic ability by prediction of future MS disability, e.g., [99], see also [100-102]. One potential avenue for future research is to evaluate the use of oxygen metabolism signals in MS prognosis. For example, Ge and colleagues' [27] research showed that lower resting brain-wide levels of oxygen metabolism were associated with both increased neurological disability and increased lesion burden in MS patients. Although these findings were cross-sectional, they suggested that oxygen metabolism could be a marker of the trajectory of disease course. To wit, future longitudinal work should examine whether measures of oxygen metabolism in early MS can predict future disease progression cf. [89]. veCMRO ${ }_{2}$ or resting oxygen metabolic markers could also be evaluated for their abilities to predict the transition from risk states (such as clinically or radiologically isolated syndrome) to clinically definite MS see [100,102,103].

A recent wave of findings related to metabolic dysfunction in MS has led to metabolic hypotheses to explain the pathophysiology of MS see [34-36]. For instance, Paling and colleagues furthered an energy failure hypothesis of the pathophysiology of MS [35,104]. These authors postulated a link between white matter damage and energy demand in MS, wherein this damage causes neuroenergetic demand to exceed the supply of metabolic substrate. This hypothesis is largely consistent with the findings of the present study, wherein the observed relative decrease in veCBF (the supply of oxygen and glucose) in MS might have limited the neurometabolic response $(\mathrm{veCMRO})$ relative to $\mathrm{HCs}$. Further, issues of oxygen extraction due to mitochondrial damage/dysfunction could have also contributed to the relative decrease in veCMRO ${ }_{2}$ for MS patients relative to HCs see [34-36].

Imaging techniques here and elsewhere have produced convincing biomarkers of MS see $[38,97,100]$. However, MS is a complex, multifaceted disease. Thus, it is not surprising that our results revealed a diverse array of measures that were accurate in classifying MS patients and HCs. The goal of this work was to examine the ability of a new marker $(\mathrm{veCMRO})$ to accurately classify MS. However, a truly prodigious advance in MS diagnostics will likely evolve from models that combine many relevant factors. It is possible that a "gold-standard" model of MS diagnostics would contain information about evoked $\mathrm{CMRO}_{2}$, along with other information like lesion count, self-reported symptomology, neuropsychological performance, and potentially other strong associates of MS not examined here (e.g., low-contrast letter acuity performance see [105], oligoclonal band status [106], retinal nerve fiber layer thickness see [38]). For instance, research from the Alzheimer's Disease Neuroimaging Initiative showed that a complement of multimodal neuroimaging, cerebrospinal fluid proteins, along with standard clinical evaluations allow for optimal prediction of conversion from mild cognitive impairment to Alzheimer's disease [107]; see also [108] for application in psychiatry.

\section{Conclusions}

This study was the first to apply cfMRI in an MS sample. Presently, the intricacies of cfMRI acquisition and post-acquisition processing probably hinder it from having an immediate impact upon routine diagnosis or tracking of MS. However, acquisition continues to be optimized and research is showing promise toward eliminating the gas-challenge component of this method, see [8], which should increase the ease of cfMRI administration and the diversity of patients in which it can be applied. With contemporary research highlighting the importance of neurometabolism in the pathophysiology of MS and continued optimization of this technique, cfMRI shows promise as a translational diagnostic/prognostic tool for MS.

Our findings demonstrated that veCMRO 2 was accurate in classifying both within- and out-of-sample observations of MS patients and HCs. Out-of-sample analyses suggested that predictive models using veCMRO ${ }_{2}$ could be useful in MS diagnostics and potentially new cases of MS. Although out-of-sample analyses provide confidence in the generalizability of our findings, larger, independent 
samples are desirable to confirm the robustness of these effects. However, the present findings represent an encouraging first step in realizing the diagnostic relevance of veCMRO 2 in $\mathrm{MS}$.

Acknowledgments: This work was supported by grants from the National Multiple Sclerosis Society (to DTO and BR; number RG-1507-04951; and to BR RG-1510-06687) and from the National Institutes of Health (to BR and HL; number 5RO1AG047972-02). The authors wish to thank Hannah Grotzinger and Judith Gallagher for their contributions to manuscript preparation.

Author Contributions: N.A.H. contributed to study design, data analysis, and wrote the manuscript. Y.S.A. and C.C. contributed to statistical analysis. M.P.T., L.H. and B.P.T. contributed to study design, data collection and analyses, and manuscript writing. M.O. and H.H., contributed to diffusion tensor imaging analyses. S.F. contributed to data collection and data processing. J.H., Jr., D.T.O. and B.R. contributed to study design, conceptualization, and manuscript writing.

Conflicts of Interest: N.A.H., Y.S.A., C.C., M.O., M.P.T., L.H., S.F., B.P.T., J.H., Jr., H.H. and B.R. declare no perceived conflicts of interests. D.T.O. received lecture fees from Acorda, Genzyme, and TEVA Neuroscience, consulting and advisory board fees from EMD Serono, Genentech, Genzyme, Novartis and TEVA Neuroscience, and research support from Biogen not related to this study.

\section{References}

1. Polman, C.H.; Reingold, S.C.; Banwell, B.; Clanet, M.; Cohen, J.A.; Filippi, M.; Fujihara, K.; Havrdova, E.; Hutchison, M.; Kappos, L.; et al. Diagnostic Criteria for Multiple Sclerosis: 2010 Revisions to the McDonald Criteria. Ann. Neurol. 2011, 69, 292-302. [CrossRef] [PubMed]

2. George, I.C.; Sati, P.; Absinta, M.; Cortese, I.C.M.; Sweeney, E.M.; Shea, C.D.; Reich, D.S. Clinical 3-Tesla FLAIR* MRI Improves Diagnostic Accuracy in Multiple Sclerosis. Mult. Scler. 2016, 22, 1578-1586. [CrossRef] [PubMed]

3. Wattjes, M.P.; Barkhof, F. High Field MRI in the Diagnosis of Multiple Sclerosis: High Field-High Yield? Neuroradiology 2009, 51, 279-292. [CrossRef] [PubMed]

4. Metcalf, M.; Xu, D.; Okuda, D.T.; Carvajal, L.; Srinivasan, R.; Kelley, D.A.C.; Mukherjee, P.; Nelson, S.J.; Vigneron, D.B.; Pelletier, D. High-Resolution Phased-Array MRI of the Human Brain and 7 Tesla: Initial Experience in Multiple Sclerosis Patients. J. Neuroimaging 2010, 20, 141-147. [CrossRef] [PubMed]

5. Oberwahrenbrok, T.; Ringelstein, M.; Jentschke, S.; Deuschle, K.; Klumbies, K.; Bellmann-Strobl, J.; Harmel, J.; Ruprecht, K.; Schippling, S.; Hartung, H.P.; et al. Retinal Ganglion Cell and Inner Plexiform Layer Thinning in Clinically Isolated Syndrome. Mult. Scler. 2013, 19, 1887-1895. [CrossRef] [PubMed]

6. Davis, T.L.; Kwong, K.K.; Weiskoff, R.M.; Rosen, B.R. Calibrated Functional MRI: Mapping the Dynamics of Oxidative Metabolism. Proc. Natl. Acad. Sci. USA 1998, 95, 1834-1839. [CrossRef] [PubMed]

7. Hoge, S.A.; Atkinson, J.; Gill, B.; Crelier, G.R.; Marrett, S.; Pike, G.B. Linear Coupling Between Cerebral Blood Flow and Oxygen Consumption in Activated Human Cortex. Proc. Natl. Acad. Sci. USA 1999, 96, 9403-9408. [CrossRef] [PubMed]

8. Hoge, R.D. Calibrated fMRI. NeuroImage 2012, 62, 930-937. [CrossRef] [PubMed]

9. Herman, P.; Sanganahalli, B.G.; Blumenfeld, H.; Hyder, F. Cerebral Oxygen Demand for Short-Lived and Steady-State Events. J. Neurochem. 2009, 109, 73-79. [CrossRef] [PubMed]

10. Herman, P.; Sanganahalli, B.G.; Blumenfeld, H.; Rothman, D.L.; Hyder, F. Quantitative Basis for Neuroimaging of Cortical Laminae with Calibrated Functional MRI. Proc. Natl. Acad. Sci. USA 2013, 110, 15115-15120. [CrossRef] [PubMed]

11. Hyder, F.; Kida, I.; Behar, K.L.; Kennan, R.P.; Maciejewski, P.K.; Rothman, D.L. Quantitative Functional Imaging of the Brain: Towards Mapping Neuronal Activity by BOLD fMRI. NMR Biomed. 2001, 14, 413-431. [CrossRef] [PubMed]

12. Hyder, F.; Rothman, D.L.; Shulman, R.G. Total Neuroenergetics Support Localized Brain Activity: Implications for the Interpretation of fMRI. Proc. Natl. Acad. Sci. USA 2002, 99, 10771-10776. [CrossRef] [PubMed]

13. Hyder, F. Neuroimaging with Calibrated FMRI. Stroke 2004, 35, 2635-2641. [CrossRef] [PubMed]

14. Lin, A.-L.; Fox, P.T.; Hardies, J.; Duong, T.Q.; Gao, J.H. Nonlinear Coupling Between Cerebral Blood Flow, Oxygen Consumption, and ATP Production in Human Visual Cortex. Proc. Natl. Acad. Sci. USA 2010, 107, 8446-8451. [CrossRef] [PubMed] 
15. Smith, A.J.; Blumenfeld, H.; Behar, K.J.; Rothman, D.L.; Shulman, R.G.; Hyder, F. Cerebral Energetics and Spiking Frequency: The Neurophysiological Basis of fMRI. Proc. Natl. Acad. Sci. USA 2002, 99, 10765-10770. [CrossRef] [PubMed]

16. He, B.J.; Snyder, A.Z.; Zempel, J.M.; Smyth, M.D.; Raichle, M.E. Electrophysiological Correlates of the Brain's Intrinsic Large-Scale Functional Architecture. Proc. Natl. Acad. Sci. USA 2008, 105, 16039-16044. [CrossRef] [PubMed]

17. Leopold, D.A.; Maier, A. Ongoing Physiological Processes in the Cerebral Cortex. NeuroImage 2012, 62, 2190-2200. [CrossRef] [PubMed]

18. Logothetis, N.K.; Pauls, J.; Augath, M.; Trinath, T.; Oeltermann, A. Neurophysiological Investigation of the Basis of the fMRI Signal. Nature 2001, 412, 150-157. [CrossRef] [PubMed]

19. Lu, H.; Zuo, Y.; Gu, H.; Waltz, J.A.; Zhan, W.; Scholl, C.A.; Rea, W.; Yang, W.; Stein, E.A. Synchronized Delta Oscillations Correlate with the Resting-State Functional MRI Signal. Proc. Natl. Acad. Sci. USA 2007, 104, 18265-18269. [CrossRef] [PubMed]

20. Zhu, Z.; Johnson, N.F.; Kim, C.; Gold, B.T. Reduced Frontal Cortex Efficiency is Associated with Lower White Matter Integrity in Aging. Cereb. Cortex 2015, 25, 138-146. [CrossRef] [PubMed]

21. Mark, C.I.; Mazerolle, E.L.; Chen, J.J. Metabolic and Vascular Origins of the BOLD Effect: Implications for Imaging Pathology and Resting-State Brain Function. J. Magn. Reson. Imaging 2015, 42, 231-246. [CrossRef] [PubMed]

22. Hutchison, J.L.; Lu, H.; Rypma, B. Neural Mechanisms of Age-Related Slowing: The $\Delta \mathrm{CBF} / \Delta \mathrm{CMRO} 2$ Ratio Mediates Age-Differences in BOLD Signal and Human Performance. Cereb. Cortex 2013, 23, 2337-2346. [CrossRef] [PubMed]

23. Hutchison, J.L.; Shokri-Kojori, E.; Lu, H.; Rypma, B. A BOLD Perspective on Age-Related Neurometabolic-Flow Coupling and Neural Efficiency Changes in Human Visual Cortex. Front. Psychol. 2013, 4, 1-12. [CrossRef] [PubMed]

24. Iannetti, G.D.; Wise, R.G. BOLD Functional MRI in Disease and Pharmacological Studies: Room for Improvement? Magn. Reson. Imaging 2007, 25, 978-988. [CrossRef] [PubMed]

25. Cader, S.; Johansen-Berg, H.; Wylezinska, M.; Palace, J.; Behrens, T.E.; Smith, S.; Matthews, P.M. Discordant White Matter N-acetylasparate and Diffusion MRI Measure Suggest that Chronic Metabolic Dysfunction Contributes to Axonal Pathology in Multiple Sclerosis. NeuroImage 2007, 36, 19-27. [CrossRef] [PubMed]

26. Pfueller, C.F.; Brandt, A.U.; Schubert, F.; Bock, M.; Walaszek, B.; Waiszies, H.; Schwenteck, T.; Dörr, J.; Bellmann-Strobl, J.; Mohr, C.; et al. Metabolic Changes in the Visual Cortex are Linked to Retinal Nerve Fiber Layer Thinning in Multiple Sclerosis. PLoS ONE 2011, 6, e18019. [CrossRef] [PubMed]

27. Hannoun, S.; Bagory, M.; Durand-Dubief, F.; Ibarrola, D.; Comte, J.C.; Confavreux, C.; Cotton, F.; Sappey-Marinier, D. Correlation of diffusion and Metabolic Alterations in Different Clinical Forms of Multiple Sclerosis. PLoS ONE 2012, 7, e32525. [CrossRef]

28. Sijens, P.E.; Irwan, R.; Potze, J.H.; Mostert, J.P.; De Keyser, J.; Ouderk, M. Analysis of the Human Brain in Primary Progressive Multiple Sclerosis with Mapping of the Spatial Distributions Using 1H MR Spectroscopy and Diffusion Tensor Imaging. Eur. Radiol. 2005, 15, 1686-1693. [CrossRef] [PubMed]

29. Sun, X.; Tanaka, M.; Kondo, S. Clinical Significance of Reduced Cerebral Metabolism in Multiple Sclerosis: A Combined PET and MRI Study. Ann. Nucl. Med. 1998, 12, 89-94. [CrossRef] [PubMed]

30. Ge, Y.; Zhang, Z.; Lu, H.; Tang, L.; Jaggi, H.; Herbert, J.; Babb, J.S.; Rusinek, H.; Grossman, R.I. Characterizing Brain Oxygen Metabolism in Patients with Multiple Sclerosis with T2-Relaxation-Under-Spin-Tagging MRI. J. Cereb. Blood Flow Metab. 2012, 32, 403-412. [CrossRef] [PubMed]

31. Dutta, R.; McDonough, J.; Yin, X.; Peterson, J.; Chang, A.; Torres, T.; Gudz, T.; Macklin, W.B.; Lewis, D.A.; Fox, R.J.; et al. Mitochondrial Dysfunction as a Cause of Axonal Degeneration in Multiple Sclerosis Patients. Ann. Neurol. 2006, 59, 478-489. [CrossRef] [PubMed]

32. Mahad, D.J.; Ziabreva, I.; Campbell, G.; Lax, N.; White, K.; Hanson, P.S.; Lassmann, H.; Turnbull, D.M. Mitochondrial Changes Within Axons in Multiple Sclerosis. Brain 2009, 132, 1161-1174. [CrossRef] [PubMed]

33. Singhal, N.K.; Li, S.; Arning, E.; Alkhayer, K.; Clements, R.; Sarcyk, Z.; Dassanayake, R.S.; Brasch, N.E.; Freeman, E.J.; Bottiglieri, T.; et al. Changes in Methionine Metabolism and Histone H3 Trimethylation are Linked to Mitochondrial Defects in Multiple Sclerosis. J. Neurosci. 2015, 35, 15170-15186. [CrossRef] [PubMed] 
34. Cambron, M.; D’haeseleer, M.; Laureys, G.; Clinckers, R.; Debruyne, J.; De Keyser, J. White-Matter Astrocytes, Axonal Energy Metabolism, and Axonal Degeneration in Multiple Sclerosis. J. Cereb. Blood Flow Metab. 2012, 32, 413-424. [CrossRef] [PubMed]

35. Paling, D.; Golay, X.; Wheeler-Kingshott, C.; Kapoor, R.; Miller, D. Energy Failure in Multiple Sclerosis and its Investigation Using MR Techniques. J. Neurol. 2011, 258, 2113-2127. [CrossRef] [PubMed]

36. Su, K.; Bourdette, D.; Forte, M. Mitochondrial Dysfunction and Neurodegeneration in Multiple Sclerosis. Front. Physiol. 2013, 4, 1-10. [CrossRef] [PubMed]

37. Frohman, E.M.; Frohman, T.C.; Zee, D.S.; McColl, R.; Galetta, S. The Neuro-Ophthalmology of Multiple Sclerosis. Lancet Neurol. 2005, 4, 111-121. [CrossRef]

38. Frohman, E.M.; Fujimoto, J.G.; Frohman, T.C.; Calabresi, P.A.; Cutter, G.; Balcer, L.J. Optical Coherence Tomography: A Window Into the Mechanisms of Multiple Sclerosis. Nat. Clin. Pract. Neurol. 2008, 4, 664-675. [CrossRef] [PubMed]

39. Graham, S.L.; Klistorner, A. Afferent Visual Pathways in Multiple Sclerosis: A Review. Clin. Exp. Ophthalmol. 2017, 45, 62-72. [CrossRef] [PubMed]

40. Kolappan, M.; Henderson, A.P.D.; Jenkins, T.M.; Wheeler-Kingshott, C.A.; Plant, G.T.; Miller, D.H. Assessing Structure and Function of the Afferent Visual Pathway in Multiple Sclerosis and Associated Optic Neuritis. J. Neurol. 2009, 256, 305-319. [CrossRef] [PubMed]

41. Alshowaeir, D.; Yiannikas, C.; Garrick, R.; Paratt, J.; Barnett, M.H.; Graham, S.L.; Klistorner, A. Latency of Multifocal Visual Evoked Potentials in Nonoptic Neuritis Eyes of Multiple Sclerosis Patients Associated with Optic Radiation Lesions. Investig. Ophthalmol. Vis. Sci. 2014, 55, 3758-3764. [CrossRef] [PubMed]

42. Hubbard, N.A.; Turner, M.; Hutchison, J.L.; Ouyang, A.; Strain, J.; Oasay, L.; Sundaram, S.; Davis, S.; Remington, G.; Brigante, R.; et al. Multiple Sclerosis-Related White Matter Microstructural Change Alters the BOLD Hemodynamic Response. J. Cereb. Blood Flow Metab. 2016, 36, 1872-1884. [CrossRef] [PubMed]

43. Hubbard, N.A.; Hutchison, J.L.; Turner, M.P.; Sundaram, S.; Oasay, L.; Robinson, D.; Strain, J.; Weaver, T.; Davis, S.L.; Remington, G.M.; et al. Asynchrony in Executive Networks Predicts Cognitive Slowing in Multiple Sclerosis. Neuropsychology 2016, 30, 75. [CrossRef] [PubMed]

44. Rao, S.M. Cognitive Function Study Group of the National Multiple Sclerosis Society. In A Manual for the Brief Repeatable Battery of Neuropsychological Tests in Multiple Sclerosis; Medical College of Wisconsin: Milwaukee, WI, USA, 1990.

45. Brandt, J.; Spencer, M.; Folstein, M. The Telephone Interview for Cognitive Status. Neuropsychiatry Neuropsychol. Behav. Neurol. 1988, 1, 111-117.

46. Verdier-Taillefer, M.H.; Roullet, E.; Cesaro, P.; Alpérovitch, A. Validation of Self-Reported Neurological Disability in Multiple Sclerosis. Int. J. Epidemiol. 1994, 23, 148-154. [CrossRef] [PubMed]

47. Perthen, J.E.; Lansing, A.E.; Liau, J.; Liu, T.T.; Buxton, R.B. Caffeine-Induced Uncoupling of Cerebral Blood Flow and Oxygen Metabolism: A Calibrated BOLD fMRI Study. NeuroImage 2008, 40, 237-247. [CrossRef] [PubMed]

48. Ware, J.E.; Kosinski, M.; Keller, S.D. SF-36 Physical and Mental Health Summary Scales: A Users' Manual; The Health Institute: Scarborough, ON, Canada; New England Medical Center: Boston, MA, USA, 1994.

49. Fisk, J.D.; Pontefract, A.; Ritvo, P.G.; Archibald, C.J.; Muarray, T.J. The impact of fatigue on patients with multiple sclerosis. Can. J. Neurol. Sci. 1994, 21, 9-14. [CrossRef] [PubMed]

50. Boringa, J.B.; Lazeron, R.H.C.; Reuling, I.E.W.; Adèr, H.J.; Pfennings, L.E.M.A.; Lindeboom, J.; de Sonneville, L.M.J.; Kalkers, N.F.; Polman, C.H. The Brief Repeatable Battery of Neuropsychological Tests: Normative Values Allow Application in Multiple Sclerosis Clinical Practice. Mult. Scler. 2001, 7, 263-267. [CrossRef] [PubMed]

51. Strauss, E.; Sherman, E.M.S.; Spreen, O. A Compendium of Neuropsychological Tests: Administration, Norms, and Commentary; American Chemical Society: Washington, DC, USA, 2006.

52. Lu, H.; van Zijl, P. Experimental Measurement of Extravascular Parenchymal BOLD Effects and Tissue Oxygen Extraction Fractions Using Multi-Echo VASO fMRI at 1.5 and 3.0 T. Magn. Reson. Med. 2005, 53, 808-816. [CrossRef] [PubMed]

53. Ances, B.M.; Liang, C.L.; Leontiev, O.; Perthen, J.E.; Fleisher, A.S.; Lansing, A.E.; Buxton, R.B. Effects of Aging on Cerebral Blood Flow, Oxygen Metabolism, and Blood Oxygen Level Dependent Responses to Visual Stimulation. Hum. Brain Mapp. 2009, 30, 1120-1132. [CrossRef] [PubMed] 
54. Buxton, R.B. Interpreting Oxygenation-Based Neuroimaging Signals: The Importance and the Challenge of Understanding Brain Oxygen Metabolism. Front. Neuroenerg. 2010. [CrossRef] [PubMed]

55. Leontiev, O.; Buxton, R.B. Reproducibility of BOLD, Perfusion, and CMRO2 Measurements with Calibrated-BOLD fMRI. NeuroImage 2007, 35, 175-184. [CrossRef] [PubMed]

56. Grubb, R.L.; Raichle, M.E.; Eichling, J.O.; Ter-Pogossian, M.M. The Effects of Changes in PaCO2 Cerebral Blood Volume, Blood Flow, and Vascular Mean Transit Time. Stroke 1974, 5, 630-639. [CrossRef] [PubMed]

57. Hubbard, N.A.; Turner, M.P.; Robinson, D.M.; Sundaram, S.; Oasay, L.; Hutchison, J.L.; Ouyang, A.; Huang, H.; Rypma, B. Attenuated BOLD Hemodynamic Response Predicted by Degree of White Matter Insult, Slows Cognition in Multiple Sclerosis. Mult. Scler. J. 2014, 20, 267.

58. Pasley, B.N.; Inglis, B.A.; Freeman, R.D. Analysis of Oxygen Metabolism Implies a Neural Origin for the Negative BOLD Response in Human Visual Cortex. NeuroImage 2007, 36, 269-276. [CrossRef] [PubMed]

59. Lin, A.; Fox, P.T.; Yang, Y.; Lu, J.; Tan, L.H.; Gao, J.H. Evaluation of MRI Models in the Measurement of CMRO2 and Its Relationship with CBF. Magn. Reson. Med. 2008, 60, 380-389. [CrossRef] [PubMed]

60. Singh, M.; Kim, S.; Kim, T. Correlation Between BOLD-fMRI and EEG Signal Changes in Response to Visual Stimulus Frequency in Humans. Magn. Reson. Med. 2003, 49, 108-114. [CrossRef] [PubMed]

61. Peng, S.L.; Ravi, H.; Sheng, M.; Thomas, B.P.; Lu, H. Searching for a Truly "Iso-Metabolic" Gas Challenge in Physiological MRI. J. Cereb. Blood Flow Metab. 2017, 37, 715-725. [CrossRef] [PubMed]

62. Xu, F.; Uh, J.; Brier, M.R.; Hart, J., Jr.; Yezhuvath, U.S.; Gu, H.; Yang, Y.; Lu, H. The Influence of Carbon Dioxide on Brain Activity and Metabolism in Conscious Humans. J. Cereb. Blood Flow Metab. 2011, 31, 58-67. [CrossRef] [PubMed]

63. Zappe, A.C.; Uludağ, K.; Oeltermann, A.; Uğurbil, K.; Logothetis, N.L. The Influence of Moderate Hypercapnia on Neural Activity in the Anesthetized Nonhuman Primate. Cereb. Cortex 2008, 18, 2666-2673. [CrossRef] [PubMed]

64. Yucel, M.A.; Evans, K.C.; Selb, J.; Huppert, T.J.; Boas, D.A.; Gagnon, L. Validation of the Hypercapnic Calibrated fMRI Method Using DOT-fMRI Fusion Imaging. NeuroImage 2014, 102, 729-735. [CrossRef] [PubMed]

65. Cox, R.W. AFNI: Software for Analysis and Visualization of Functional Magnetic Resonance Neuroimages. Comput. Biomed. Res. 1996, 29, 162-173. [CrossRef] [PubMed]

66. FMRIB Analysis Group. FMRIB Software Library v5.0. Available online: https://fsl.fmrib.ox.ac.uk/fsl/ fslwiki (accessed on 3 June 2017).

67. Liu, T.T.; Wong, E.C. A Signal Processing Model for Arterial Spin Labeling Functional MRI. NeuroImage 2005, 24, 207-215. [CrossRef] [PubMed]

68. Hutchison, J.L.; Hubbard, N.A.; Brigante, R.M.; Turner, M.; Sandoval, T.I.; Hillis, G.A.; Weaver, T.; Rypma, B. The Efficiency of fMRI Region of Interest Analysis Methods for Detecting Group Differences. J. Neurosci. Methods 2014, 226, 57-65. [CrossRef] [PubMed]

69. Smith, S.M.; De Stefano, N.; Jenkinson, M.; Matthews, P.M. Normalised Accurate Measurement of Longitudinal Brain Change. J. Comput. Assist. Tomogr. 2001, 25, 466-475. [CrossRef] [PubMed]

70. Hart, J., Jr.; Kraut, M.A.; Womack, K.B.; Strain, J.; Didehbani, N.; Bartz, E.; Conover, H.; Mansinghani, S.; Lu, H.; Cullum, C.M. Neuroimaging of Cognitive Dysfunction and Depression in Aging Retired National Football League Players. JAMA Neurol. 2013, 70, 326-335. [CrossRef] [PubMed]

71. Dice, L.R. Measures of the Amount of Ecologic Association between Species. Ecology 1945, 26, $297-302$. [CrossRef]

72. Zhang, L.; Dean, D.; Liu, J.Z.; Sahgal, V.; Wang, X.; Yue, G.H. Quantifying Degeneration of White Matter in Normal Aging Using Fractal Dimension. Neurobiol. Aging 2007, 28, 1543-1555. [CrossRef] [PubMed]

73. Ghassemi, R.; Narayana, S.; Banwell, B.; Sled, J.G.; Shroff, M.; Arnold, D.L. Quantitative Determination of Regional Lesion Volume and distribution in Children and Adults with Relapsing-Remitting Multiple Sclerosis. PLoS ONE 2014, 9, e85741. [CrossRef] [PubMed]

74. Jones, D.K.; Simmons, A.; Williams, S.C.; Horsfield, M.A. Non-invasive Assessment of Axonal Fiber Connectivity in the Human Brain via Diffusion Tensor MRI. Magn. Reson. Med. 1999, 42, 37-41. [CrossRef]

75. Woods, R.P.; Grafton, S.T.; Holmes, C.J.; Cherry, S.R.; Mazziotta, J.C. Automated Image Registration: I. General Methods and Intrasubject, Intramodality Validation. J. Comput. Assist. Tomogr. 1998, 22, 139-152. [CrossRef] [PubMed] 
76. Jiang, H.; van Zijl, P.C.J.K.; Pearlson, G.D.; Mori, S. DtiStudio: Resource Program for Diffusion Tensor Computation and Fiber Bundle Tracking. Comput. Methods Programs Biomed. 2006, 81, 106-116. [CrossRef] [PubMed]

77. Smith, S.M.; Jenkinson, M.; Johansen-Berg, H.; Rueckert, D.; Nichols, T.E.; Mackay, C.E.; Watkins, K.E.; Ciccarelli, O.; Cader, M.Z.; Matthews, P.M.; et al. Tract-Based Spatial Statistics: Voxelwise Analysis of Multi-Subject Diffusion Data. NeuroImage 2006, 3, 1487-1505. [CrossRef] [PubMed]

78. Huang, H.; Gundapuneedi, T.; Rao, U. White Matter Disruptions in Adolescents Exposed to Childhood Maltreatment and Vulnerability to Psychopathology. Neuropsychopharmacology 2012, 37, 2693-2701. [CrossRef] [PubMed]

79. Huang, H.; Fan, X.; Weiner, M.; Martin-Cook, K.; Xiao, G.; Davis, J.; Devous, M.; Rosenberg, R. Distinctive Disruption Patterns of White Matter Tracts in Alzheimer's Disease with Full Diffusion Tensor Characterization. Neurobiol. Aging 2012, 33, 2029-2045. [CrossRef] [PubMed]

80. Ouyang, M.; Cheng, H.; Mishra, V.; Gong, G.; Mosconi, M.; Sweeney, J.; Peng, Y.; Huang, H. Atypical age-dependent effects of autism on white matter microstructure in children of 2-7 years. Hum. Brain Mapp. 2016, 37, 819-832. [CrossRef] [PubMed]

81. Mori, S.; Oishi, K.; Jiang, H.; Jiang, L.; Li, X.; Akhter, K.; Hua, K.; Faria, A.V.; Mahmood, A.; Woods, R.; et al. Stereotaxic White Matter Atlas Based on Diffusion Tensor Imaging in an ICBM Template. NeuroImage 2008, 40, 570-582. [CrossRef] [PubMed]

82. Iglewicz, B.; Hoaglin, D. Volume 16: How to Detect and Handle Outliers. In The ASQC Basic References in Quality Control: Statistical Techniques; Mykytka, E.F., Ed.; American Society for Quality Control, Statistics Division: Milwaukee, WI, USA, 1993.

83. Gabrieli, J.D.E.; Ghosh, S.S.; Whitfield-Gabrieli, S. Prediction as a Humanitarian and Pragmatic Contribution from Human Cognitive Neuroscience. Neuron 2015, 85, 11-26. [CrossRef] [PubMed]

84. Efron, B. Better Bootstrap Confidence Intervals. J. Am. Stat. Assoc. 1987, 82, 171-185. [CrossRef]

85. Kohavi, R. A Study of Cross-Validation and Bootstrap for Accuracy Estimation and Model Selection. In Proceedings of the Fourteenth International Joint Conference on Artificial Intelligence, Montreal, QC, Canada, 20-25 August 1995; Morgan Kaufmann Publishers: San Mateo, CA, USA, 1995; Volume 2, pp. 1137-1143.

86. Ojala, M.; Garriga, G.C. Permutation Tests for Studying Classifier Performance. J. Mach. Learn. Res. 2010, 11, 1833-1863.

87. Marshall, O.; Lu, H.; Brisset, J.C.; Xu, F.; Liu, P.; Herbert, J.; Grossman, R.I.; Ge, Y. Impaired Cerebrovascular Reactivity in Multiple Sclerosis. JAMA Neurol. 2014, 71, 1275-1281. [CrossRef] [PubMed]

88. Laron, M.; Cheng, H.; Zhang, B.; Schiffman, J.S.; Tang, R.A.; Frishman, L.J. Comparison of Multifocal Visual Evoked Potential, Standard Automated Perimetry and Optical Coherence Tomography in Assessing Visual Pathways in Multiple Sclerosis Patients. Mult. Scler. 2010, 16, 412-426. [CrossRef] [PubMed]

89. Fraser, C.; Klistorner, A.; Graham, S.; Garrick, R.; Billson, F.; Grigg, J. Multifocal Visual Evoked Potential Latency Analysis: Predicting Progression to Multiple Sclerosis. Arch. Neurol. 2006, 63, 847-850. [CrossRef] [PubMed]

90. Ruseckaite, R.; Maddess, T.; Danta, G.; Lueck, C.J.; James, A.C. Sparse Multifocal Stimuli for the Detection of Multiple Sclerosis. Ann. Neurol. 2005, 57, 904-913. [CrossRef] [PubMed]

91. Pantano, P.; Mainero, C.; Caramia, F. Functional Brain Reorganization in Multiple Sclerosis: Evidence from fMRI Studies. J. Neuroimaging 2006, 16, 104-114. [CrossRef] [PubMed]

92. White, A.T.; Lee, J.N.; Light, A.R.; Light, K.C. Brain Activation in Multiple Sclerosis: A BOLD fMRI Study of the Effects of Fatiguing Hand Exercise. Mult. Scler. 2009, 15, 580-586. [CrossRef] [PubMed]

93. Chiaravalloti, N.D.; Hillary, F.G.; Ricker, J.H.; Christodoulou, C.; Kalnin, A.J.; Liu, W.C.; Steffener, J.; DeLuca, J. Cerebral Activation Patterns During Working Memory Performance in Multiple Sclerosis using fMRI. J. Clin. Exp. Neuropsychol. 2005, 27, 33-54. [CrossRef] [PubMed]

94. Genova, H.M.; Sumowski, J.F.; Chiaravalloti, N.; Voelbel, G.T.; DeLuca, J. Cognition in Multiple Sclerosis: A Review of Neuropsychological and fMRI Research. Front. Biosci. 2009, 14, 1730-1744. [CrossRef]

95. Sweet, L.H.; Rao, S.M.; Primeau, M.; Durgerian, S.; Cohen, R.A. Functional Magnetic Resonance Imaging Response to Increased Verbal Working Memory Demands Among Patients with Multiple Sclerosis. Hum. Brain. Mapp. 2006, 27, 28-36. [CrossRef] [PubMed] 
96. Genova, H.M.; Hillary, F.G.; Wylie, G.; Rypma, B.; DeLuca, J. Examination of Processing Speed Deficits in Multiple Sclerosis Using Functional Magnetic Resonance Imaging. J. Int. Neuropsychol. Soc. 2009, 15, 383-393. [CrossRef] [PubMed]

97. Comabella, M.; Sastre-Garriga, J.; Montalban, X. Precision Medicine in Multiple Sclerosis: Biomarkers for Diagnosis, Prognosis, and Treatment Response. Curr. Opin. Neurol. 2016, 29, 254-262. [CrossRef] [PubMed]

98. Pulicken, M.; Gordon-Lipkin, E.; Balcer, L.J.; Frohman, E.; Cutter, G.; Calabresi, P.A. Optical Coherence Tomography and Disease Subtype in Multiple Sclerosis. Neurology 2007, 69, 2085-2092. [CrossRef] [PubMed]

99. Fisniku, L.K.; Brex, P.A.; Altmann, D.R.; Miszkiel, K.A.; Benton, C.E.; Lanyon, R.; Thompson, A.J.; Miller, D.H. Disability and T2 MRI Lesions: A 20-Year Follow-Up of Patients with Relapse Onset of Multiple Sclerosis. Brain 2008, 131, 808-817. [CrossRef] [PubMed]

100. Lebrun, C.; Bensa, C.; Debouverie, M.; Wiertlevski, S.; Brassat, D.; de Seze, J.; Rumbach, L.; Pelletier, J.; Labauge, P.; Brochet, B.; et al. Association Between Clinical Conversion to Multiple Sclerosis in Radiologically Isolated Syndrome and Magnetic Resonance Imaging, Cerebrospinal Fluid, and Visual Evoked Potential. Arch. Neurol. 2009, 66, 841-846. [CrossRef] [PubMed]

101. Leocanti, L.; Rocca, M.A.; Comi, G. MRI and Neurophysiological Measures to Predict Course, Disability and Treatment Response in Multiple Sclerosis. Curr. Opin. Neurol. 2016, 29, 243-253. [CrossRef] [PubMed]

102. Okuda, D.T.; Mowry, E.M.; Cree, B.A.C.; Crabtree, E.C.; Goodin, D.S.; Waubant, E.; Pelletier, D. Asymptomatic Spinal Cord Lesions Predict Disease Progression in Radiologically Isolated Syndrome. Neurology 2011, 76, 686-692. [CrossRef] [PubMed]

103. Stromillo, M.L.; Giorgio, A.; Rossi, F.; Battaglini, M.; Hakiki, B.; Malentacchi, G.; Santangelo, M.; Gasperini, C.; Bartolozzi, M.L.; Portaccio, E.; et al. Brain metabolic changes suggestive of axonal damage in radiologically isolated syndrome. Neurology 2013, 80, 2090-2094. [CrossRef] [PubMed]

104. Campbell, G.R.; Worrall, J.T.; Mahad, D.J. The Central Role of Mitochondrial in Axonal Degeneration in Multiple Sclerosis. Mult. Scler. 2014, 20, 1806-1813. [CrossRef] [PubMed]

105. Balcer, L.J.; Raynowska, J.; Nolan, R.; Galetta, S.L.; Kapoor, R.; Benedict, R.; Phillips, G.; LaRocca, N.; Hudson, L.; Rudick, R.; et al. Validity of Low-Contrast Letter Acuity as a Visual Performance Outcome Measure for Multiple Sclerosis. Mult. Scler. 2017, 23, 734-747. [CrossRef] [PubMed]

106. Link, H.; Huang, Y.-M. Oligoclonal Bands in Multiple Sclerosis Cerebrospinal Fluid: An Update on Methodology and Clinical Usefulness. J. Immunol. 2006, 180, 17-28. [CrossRef] [PubMed]

107. Shaffer, J.L.; Petrella, J.R.; Sheldon, F.C.; Choudhury, K.R.; Calhoun, V.D.; Coleman, R.E.; Doraiswamy, P.M. Predicting Cognitive Decline in Subjects at Risk for Alzheimer Disease by Using Combined Cerebrospinal Fluid, MR Imaging, and PET Biomarkers. Radiology 2013, 266, 583-591. [CrossRef] [PubMed]

108. Whitfield-Gabrieli, S.; Ghosh, S.S.; Nieto-Castanon, A.; Saygin, Z.; Doehrmann, O.; Chai, X.J.; Reynolds, G.O.; Hofmann, S.G.; Pollack, M.H.; Gabrieli, J.D.E. Brain Connectomics Predict Response to Treatment in Social Anxiety Disorder. Mol. Psychiatry 2015, 21, 680-685. [CrossRef] [PubMed] 